\title{
Prediction and Characterization of RXLR Effectors in Pythium Species
}

\author{
Gan Ai, ${ }^{1}$ Kun Yang, ${ }^{1}$ Wenwu Ye, ${ }^{1}$ Yuee Tian, ${ }^{1,2}$ Yaxin Du, ${ }^{1}$ Hai Zhu, ${ }^{1}$ Tianli Li, ${ }^{1}$ Qingyue Xia, ${ }^{1}$ \\ Danyu Shen, ${ }^{1}$ Hao Peng, ${ }^{3}$ Maofeng Jing, ${ }^{1}$ Ai Xia, ${ }^{1}$ and Daolong Dou ${ }^{1,+}$ \\ ${ }^{1}$ College of Plant Protection, Nanjing Agricultural University, Nanjing 210095, China \\ ${ }^{2}$ Department of Plant Protection, Henan University of Science and Technology, Luoyang 471000, China \\ ${ }^{3}$ Department of Crop and Soil Sciences, Washington State University, Pullman, WA, U.S.A.
}

Accepted 23 April 2020.

RXLR effectors, a class of secreted proteins that are transferred into host cells to manipulate host immunity, have been reported to widely exist in oomycetes, including those from genera Phytophthora, Hyaloperonospora, Albugo, and Saprolegnia. However, in Pythium species, no RXLR effector has yet been characterized, and the origin and evolution of such virulent effectors are still unknown. Here, we developed a modified regular expression method for de novo identification of RXLRs and characterized 359 putative RXLR effectors in nine Pythium species. Phylogenetic analysis revealed that all oomycetous RXLRs formed a single superfamily, suggesting that they might have a common ancestor. RXLR effectors from Pythium and Phytophthora species exhibited similar sequence features, protein structures, and genome locations. In particular, there were significantly more RXLR proteins in the mosquito biological control agent $P$. guiyangense than in the other eight Pythium species, and $P$. guiyangense RXLRs might be the result of gene duplication and genome rearrangement events, as indicated by synteny analysis. Expression pattern analysis of RXLR-encoding genes in the plant pathogen $P$. ultimum detected transcripts of the majority of the predicted $R X L R$ genes, with some RXLR effectors induced in infection stages and one RXLR showing necrosis-inducing activity. Furthermore, all predicted $R X L R$ genes were cloned from two biocontrol agents, $P$. oligandrum and $P$. periplocum, and three of the $R X L R$ genes were found to induce a defense response in Nicotiana benthamiana. Taken together, our findings represent the first evidence of RXLR effectors in Pythium species, providing valuable information on their evolutionary patterns and the mechanisms of their interactions with diverse hosts.

Gan Ai and Kun Yang contributed equally to this work.

${ }^{\dagger}$ Corresponding author: D. Dou, Email: ddou@njau.edu.cn

Funding: This project was supported by grants from the Fundamental Research Funds for the Central Universities (KYT202001 and JCQY201901), the National Natural Science Foundation of China (31625023 and 31721004) and the Special Fund for Agro-scientific Research in the Public Interest (201503112).

*The $\boldsymbol{e}$-Xtra logo stands for "electronic extra" and indicates that a supplementary figures file and nine supplementary tables are published online.

The author(s) declare no conflict of interest.

๑) 2020 The American Phytopathological Society
Keywords: gene evolution, oomycete, Pythium, pathogenicity, RXLR effector

Endless arms races between microbial pathogens and host plants are the main driving force of the coevolution of these organisms (Jones and Dangl 2006). Upon pathogen infection, plants trigger a series of defense responses by the recognition of conserved pathogen-associated molecular patterns (PAMPs) or avirulence effectors of pathogens with a diverse group of receptors (Monaghan and Zipfel 2012). As a counterdefensive tactic, numerous plant pathogens, such as bacteria, nematodes, fungi, and oomycetes, deliver a repertoire of effector proteins into hosts to suppress host immunity and facilitate infections (Jones and Dangl 2006; Latijnhouwers et al. 2003). RXLR proteins are a group of effectors initially identified from $P h y$ tophthora species that contain conserved RXLR-dEER motifs at $\mathrm{N}$ terminals, which function by entering host cells, and highly divergent C-terminals, which are associated with effector activity (Dou and Zhou 2012; Whisson et al. 2007). Many RXLR effectors have been reported to induce cell death in plants. For example, a broad survey of Phytophthora sojae RXLR effectors showed that 11 of the effectors could trigger cell death, chlorosis, or mottling in $N$. benthamiana leaves (Wang et al. 2011). Another effector, PcRXLR207, from Phytophthora capsici, induces host cell death to facilitate the transition from biotrophy to necrotrophy ( $\mathrm{Li}$ et al. 2019). Additionally, some RXLRs are avirulence proteins that exhibit gene-for-gene interactions with specific host resistance proteins and trigger hypersensitive responses in plants (Anderson et al. 2015). Thus far, most studies of RXLRs have focused on members of genera Phytophthora and Hyaloperonospora.

To date, several bioinformatics approaches have been developed to identify RXLRs from Hyaloperonospora and Phytophthora species. A pilot method, which was designed based on the first 30 residues of signal peptides (SPs) and the following 30 residues of RXLR motifs, was used to characterize RXLRs in Hyaloperonospora parasitica, Phytophthora ramorum, and Phytophthora sojae (Win et al. 2007). Later, the hidden Markov model (HMM) in combination with regular expression (regex) methods searching for the RXLR-dEER string was used to identify RXLRs in three Phytophthora species (Whisson et al. 2007). A third RXLR-identification approach is the homology searching method, which was applied to predict 370 and 392 RXLRs in Phytophthora ramorum and Phytophthora sojae, respectively (Jiang et al. 2008). RXLR effectors were identified genome-wide in different Hyaloperonospora and Phytophthora species using the above three 
methods with different thresholds. For example, the three approaches were combined to characterize RXLRs in Plasmopara viticola, a pathogen on grapevine (Yin et al. 2017).

RXLR effectors from other genera often contain a degenerate RXLR-dEER motif. Therefore, modified methods are most acceptable for the identification of RXLR effectors in species of genera other than Hyaloperonospora and Phytophthora. For instance, 26 Ac-RxL effectors were identified in Albugo candida by searching for the RXL string within proteins containing SPs. These Ac-RxLs induced cell death through effector activity, despite containing only a degenerate RXLR-dEER motif (Links et al. 2011). In Albugo laibachii, 25 RXLR and 24 RXLQ effectors were found, using similar methods, and two of the effectors were functionally analyzed (Kemen et al. 2011). An RXLR effector from a fish-infecting oomycete, Saprolegnia parasitica, was identified by searching SPs and RXLR strings and it functioned by entering the host cells to promote virulence (Wawra et al. 2012).

The genus Pythium belongs to order Pythiales, an order closely related to Peronosporales, Albuginales, and Saprolegniales (McCarthy and Fitzpatrick 2017). Unlike Phytophthora species, which are mostly plant pathogens, Pythium species have a wide range of hosts and occupy multiple ecological niches. Many Pythium species, including $P$. ultmum, $P$. iwayamai, and $P$. aphanidermatum, cause a wide variety of diseases in plants (Adhikari et al. 2013; Lévesque et al. 2010), whereas $P$. insidiosum is a notorious pathogen infecting humans and animals (Rujirawat et al. 2018). Interestingly, some Pythium species, such as $P$. oligandrum and $P$. periplocum, are used as mycoparasitic biocontrol agents, since they can infect fungal hosts and induce plant defense responses (Benhamou et al. 1997; Paul 1999; Takenaka et al. 2003). Likewise, P. guiyangense is a facultative mosquito pathogen and an effective biological control agent for management of mosquitos (Shen et al. 2019). Until now, no RXLR-encoding genes in Pythium spp. have been reported in published genome databases using HMM, regex, or modified methods (Adhikari et al. 2013; Lévesque et al. 2010; Rujirawat et al. 2018; Shen et al. 2019). For example, the HMM method with RXLR string searching was used to identify RXLR effectors in Pythium ultimum, but no RXLR candidates were characterized (Lévesque et al. 2010). The same conclusion was drawn in other Pythium genomes (Adhikari et al. 2013; Rujirawat et al. 2018). Therefore, it remains unclear whether Pythium genomes encode RXLR effectors. The molecular roles of RXLR effectors in the interactions between Pythium species and their broad hosts are underexplored.

In this study, we developed a modified method for de novo identification of RXLRs in the draft genome sequences of nine Pythium species and performed comprehensive genomic analysis on the predicted RXLRs. Our results suggested that Pythium RXLRs form a single superfamily with all other known oomycetous RXLRs and share similar sequence divergence, disorder content, and genome location features. Four novel RXLRs from $P$. ultimum, $P$. oligandrum, and $P$. periplocum were functionally analyzed, and our evidence demonstrated that they were functional RXLR effectors inducing plant cell death. Overall, our findings reveal the wide occurrence of RXLRs in Pythium species at the whole-genome level, demonstrate the effector activities of selected Pythium RXLRs, and provide a solid platform for investigating the diversified roles of Pythium RXLRs in pathogenicity.

\section{RESULTS}

\section{De novo identification of RXLR effectors.}

No Pythium RXLR effector has been previously identified, although numerous RXLRs have been reported in phylogenetically close species (Adhikari et al. 2013; Lévesque et al. 2010; Rujirawat et al. 2018; Shen et al. 2019). Here, we developed a de novo identification method with a modified regex model to screen RXLR candidates in nine Pythium species (Fig. 1A). The wellstudied genomes of Phytophthora sojae, Phytophthora ramorum, and Hyaloperonospora arabidopsidis were used as references, and two diatom genomes were also included in the analysis (Fig. 1B; Supplementary Table S1). All open reading frames (ORFs) were retrieved from each genome because almost all reported $R X L R$ genes lack introns (Jiang et al. 2008). Sequences were considered as SORFs (ORFs encoding a putative secretory protein) if their encoding proteins contained an SP but lacked a transmembrane region (TM).

In total, 311,164 sequences were obtained, with 12,490 to 33,431 sORFs found in each Pythium species, similar to the numbers of sORFs in genera Hyaloperonospora and Phytophthora (12,830 to 25,178 sORFs). Interestingly, only 47 to 12,213 sORFs were identified in the nonoomycetes (Supplementary Table S1). Significantly more sORFs were found in oomycetes than in other species $(P<2.2 \mathrm{E}-16$, Fisher's exact test), indicating the occurrence of more expansion events in secretory protein-encoding genes in oomycetes than in nonoomycetes.

Since some functionally verified RXLR effectors contain degenerate dEER motifs (Supplementary Table S2), the original regex model (SP. $\{1,96\}$ R.LR. $\{1,40\}[\mathrm{ED}][\mathrm{ED}][\mathrm{KR}])$ (Whisson et al. 2007) was modified (SP. $\{1,40\} R . L R$. $\{1,40\}([\mathrm{ED}] .[\mathrm{ED}][\mathrm{KR}] \mid[\mathrm{ED}][\mathrm{ED}] . \quad\{0,3\}[\mathrm{KR}]$ ) (Fig. 1A) to allow matching of these atypical RXLRs. In total, 1,146 RXLR candidates were identified using this modified model (Fig. 1B). We found 63, 282 and 285 RXLRs in $H$. arabidopsidis, Phytophthora ramorum, and Phytophthora sojae, respectively. They are all subsets of previously identified RXLRs and accounted for 42,53 , and $42 \%$ of the total sets, respectively (Baxter et al. 2010; Jiang et al. 2008; Win et al. 2007). In contrast, only 0 to 9 RXLRs were predicted in fungi, nematodes, or bacteria. These control results demonstrate both the high reliability and the low false-positive rate of our method. Twenty-one to 78 putative RXLRs were identified in each Pythium species. All predicted Pythium RXLR proteins contained a conserved SP, an RXLR motif, and a dEER motif, in which two acidic amino acids (D or E) were enriched and were followed by a conserved basic amino acid (R or K) (Fig. 1C; Supplementary Fig. S1).

To test the reliability of RXLR prediction in Pythium spp., an enrichment assay was conducted by comparing the RXLR number in each oomycete species with the RXLR number in the fungal pathogen Botrytis cinerea (randomly selected as a control). All oomycetes, including the Pythium species, showed significant enrichment of RXLR sequences $(P<0.01$, Fisher's exact test) (Supplementary Table S3). Enrichment was not observed in non-stramenopiles species $(P>0.05$, Fisher's exact test). Next, a permutation test was performed to evaluate whether the predicted RXLR effectors occurred randomly. We permuted the 90 after-SP residues of all sORFs and reperformed the RXLR search with the modified model 100 times to estimate the false-positive rates. In general, few numbers RXLR predictions were generated from the permuted sequences, indicating that the vast majority of oomycete RXLRs were not predicted by chance (Supplementary Table S4). For example, 35 RXLRs were predicted in P. oligandrum, whereas only one RXLR was detected, on average, in its permuted sequences. In addition to their presence in all examined oomycetes, including Pythium species, RXLR sequences were also identified in diatoms (20 in Thalassiosira pseudonana and 16 in Phaeodactylum tricornutum) with significant enrichment $(P<0.01$, Fisher's exact test). These sequences might be the 
precursors of RXLR effectors that help diatoms compete with other organisms in complex environments.

\section{The evolutionary patterns of oomycete RXLRs.}

Despite the high divergence of RXLR proteins resulting from the host-pathogen arms race, RXLR effectors from Phytophthora sojae and Phytophthora ramorum exhibited significant relatedness, suggesting that hundreds of fast-evolving RXLRs in these two species might be derived from a single common ancestor (Jiang et al. 2008). Therefore, we used BLASTP software to analyze whether the predicted Pythium RXLRs belonged to the same evolutionary theme. The highly similar $\mathrm{SP}$ regions were removed to avoid interference. Using a BLASTP E value $<1$ as the cutoff, 840 RXLR proteins had significant hits to one or more other RXLRs. In total, 15,071 RXLR pairs were identified that formed a large relatedness network (Fig. 2A). RXLRs from Phytophthora spp. had a higher within-genus relatedness level than those from genera Pythium and Hyaloperonospora, suggesting a larger contribution of recent gene expansion events in Phytophthora spp. than
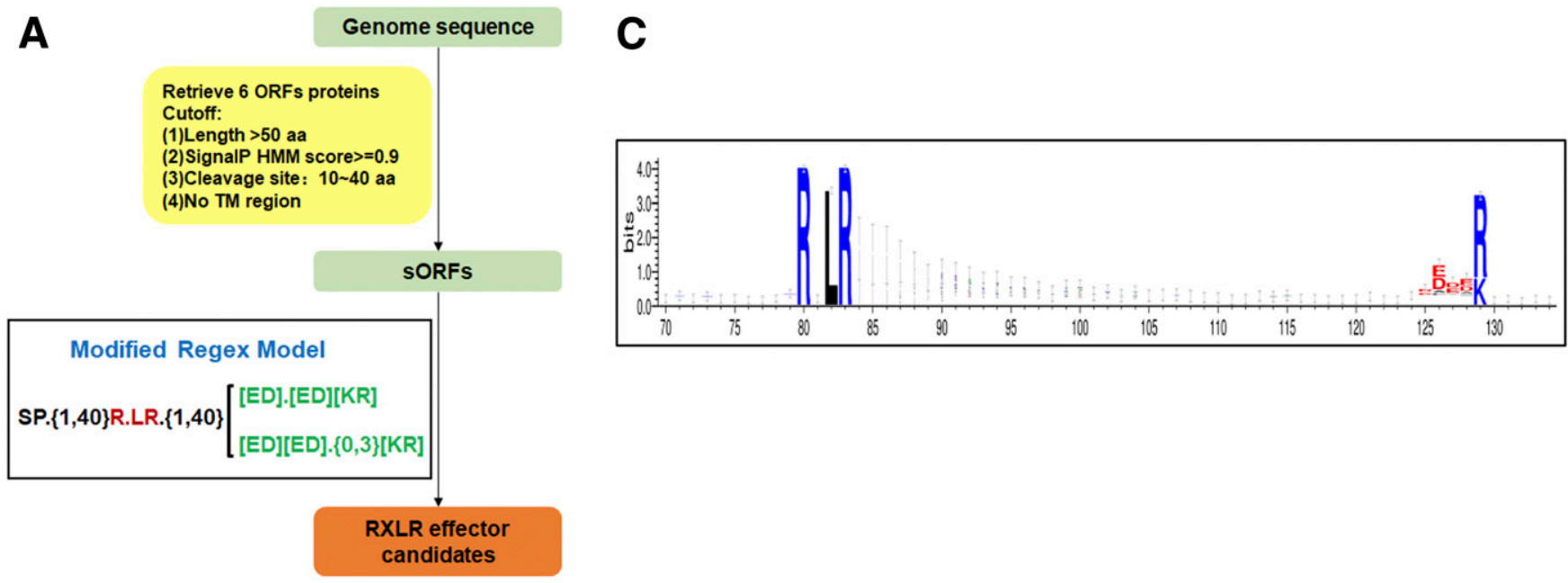

B
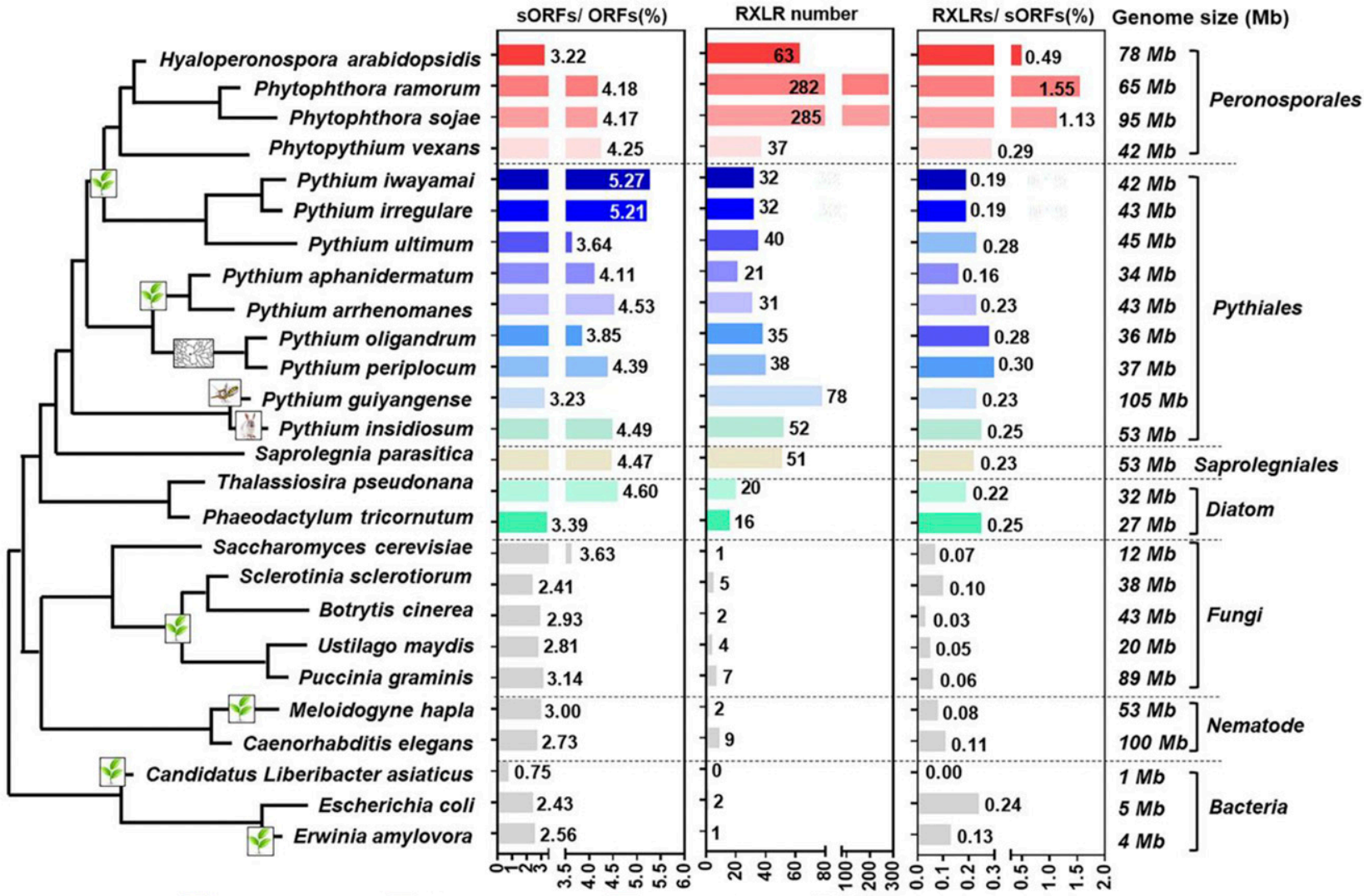

Plant pathogen

Animal pathogen

Fig. 1. De novo identification of RXLR effectors in Pythium species. A, The RXLR effector identification pipeline. sORFs (open reading frames [ORFs] encoding a putative secretory protein) indicate ORFs encoding secretory proteins with a signal peptide (SP) but without a transmembrane region (TM). B, Summary of predicted RXLRs. The phylogeny of the 26 species is based on data from the Taxonomy Database and previous studies. The ratios of sORFs to whole ORFs, the counts of RXLR candidates, and the ratios of RXLRs to sORFs in each species are shown in boxplots following the species names. The genome size of each species is shown after the corresponding boxplot. C, Weblogo of the RXLR-dEER motifs of Pythium RXLR effectors. 
in Pythium and Hyaloperonospora species. We found three clusters sharing little relatedness with Phytophthora RXLRs, which indicated relative evolutionary independence. Almost all RXLRs in these clusters were from Pythium spp. The three clusters were named cluster $1(\mathrm{C} 1)$, cluster $2(\mathrm{C} 2)$, and cluster 3 (C3) (Fig. 2A). For example, the average sequence identity of the 22 RXLRs in C1 was 54\%. A Peptidase_S8 domain (PF00082.22), which was absent in Phytophthora spp., was found in the C-termini of $21 \mathrm{C} 1 \mathrm{RXLRs}$.

Conserved RXLRs may play critical effector roles in pathogen virulence (Deb et al. 2018). Analysis of shared sequence identity (peptides with BLASTP hit E value $<1 \mathrm{e}-5$ and identity $>30 \%$ ) revealed 67, 93, and 28 Pythium RXLRs conserved at an intraspecies, intragenus, and intergenus level, respectively (Supplementary Table S5), suggesting that Pythium RXLRs share a common ancestor with RXLRs from other genera and were only slightly expanded after species divergence. These conserved RXLRs may be essential effectors for pathogens and deserve more attention in future studies.

Phylogenetic analysis was performed to further elucidate the evolutionary relationships among oomycete RXLRs as well as RXLR-like proteins from diatoms. Due to the hostpathogen arms race, RXLR C-termini (after the dEER motif) are much more divergent (Win et al. 2007) than the relatively conserved N-termini of RXLRs (Jiang et al. 2008; Kale et al. 2010). Therefore, when building the phylogenetic tree, Cterminal and SP regions were discarded to reflect RXLR evolutionary relatedness with minimal interferences from host coevolution and secretory signal sequences. Except for PyolRXLR33 and HyarRXLR1, all other 1,111 RXLRs formed a large clade (bootstrap value $=100$ ), indicating that they belong to a single superfamily. Using bootstrap value $>80$ as the criteria, 972 RXLRs were divided into 105 subfamilies with member sizes ranging from two to 112 (Supplementary Table S6). No significant divergence was detected among Peronosparales, Pythiales, Saprolegniales, and diatom RXLRs (Fig. 2B). Thirty-nine and six subfamilies contained 119 and 28 RXLRs exclusively from Peronosparales and Pythiales species, respectively. All other subfamilies harbored RXLRs from at least two different genera. Taken together, the phylogenetic results suggest a common ancestor shared by almost all RXLR and RXLR-like proteins, with species-specific expansion that was much less detected in Pythium spp. than in Phytophthora spp.

\section{Rapid evolution and abundant disorder content of Pythium RXLRs.}

The highly divergent RXLRs of Phytophthora and Hyaloperonospora species are among the most rapidly evolving portions of their proteomes (Jiang et al. 2008; Win et al. 2007). Similarly, Pythium RXLRs shared low identities in our study. On average, only $37 \%$ identity was detected between all closest RXLR ortholog pairs within the Pythium genus. In contrast, we randomly selected 300 Pythium proteins and found a much higher average sequence identity (67\%) associated with their closest ortholog pairs (Fig. 3A). In our study, 233 (65\%) Pythium RXLRs failed to form any ortholog pair, whereas only 10 of 300 randomly selected Pythium proteins lacked orthologs (Fig. 3A). Furthermore, 236 (66\%) Pythium RXLRs showed more than $50 \%$ sequence divergence (Fig. 3A).

Phytophthora RXLRs have high disorder content, which contributes to their effector activities (Shen et al. 2017). Our analysis demonstrated that the disorder content in Pythium RXLRs was high as well. The mean percentages of disordered regions in randomly selected Pythium proteins, Pythium RXLRs, and Phytophthora sojae RXLRs were 27.17, 45.48, and $36.89 \%$, respectively (Fig. 3B). Pythium RXLRs showed obviously high disorder contents that were even higher than those of Phytophthora sojae. Over 64\% Pythium RXLRs had $30 \%$ or more disordered residues, which can be found in only $43.67 \%$ of randomly selected Pythium proteins (Fig. 3B).

\section{Pythium RXLRs are predominantly located in gene-sparse regions.}

Phytophthora RXLR genes are preferably located in genesparse regions (Haas et al. 2009). Both the $5^{\prime}$ and the $3^{\prime}$ average intergenic distances of the Phytophthora sojae RXLR genes predicted in this study were significantly longer than those of the complete Phytophthora sojae genes $(P<0.05$, Student's $t$ test). The mean $5^{\prime}$-end intergenic distance of $R X L R$ genes was $3.20 \mathrm{~kb}$, with a whole-genome mean of $0.91 \mathrm{~kb}$. The average RXLR 3' intergenic distance of $3.31 \mathrm{~kb}$ was also much longer than the $3^{\prime}$ intergenic distance of complete Phytophthora sojae

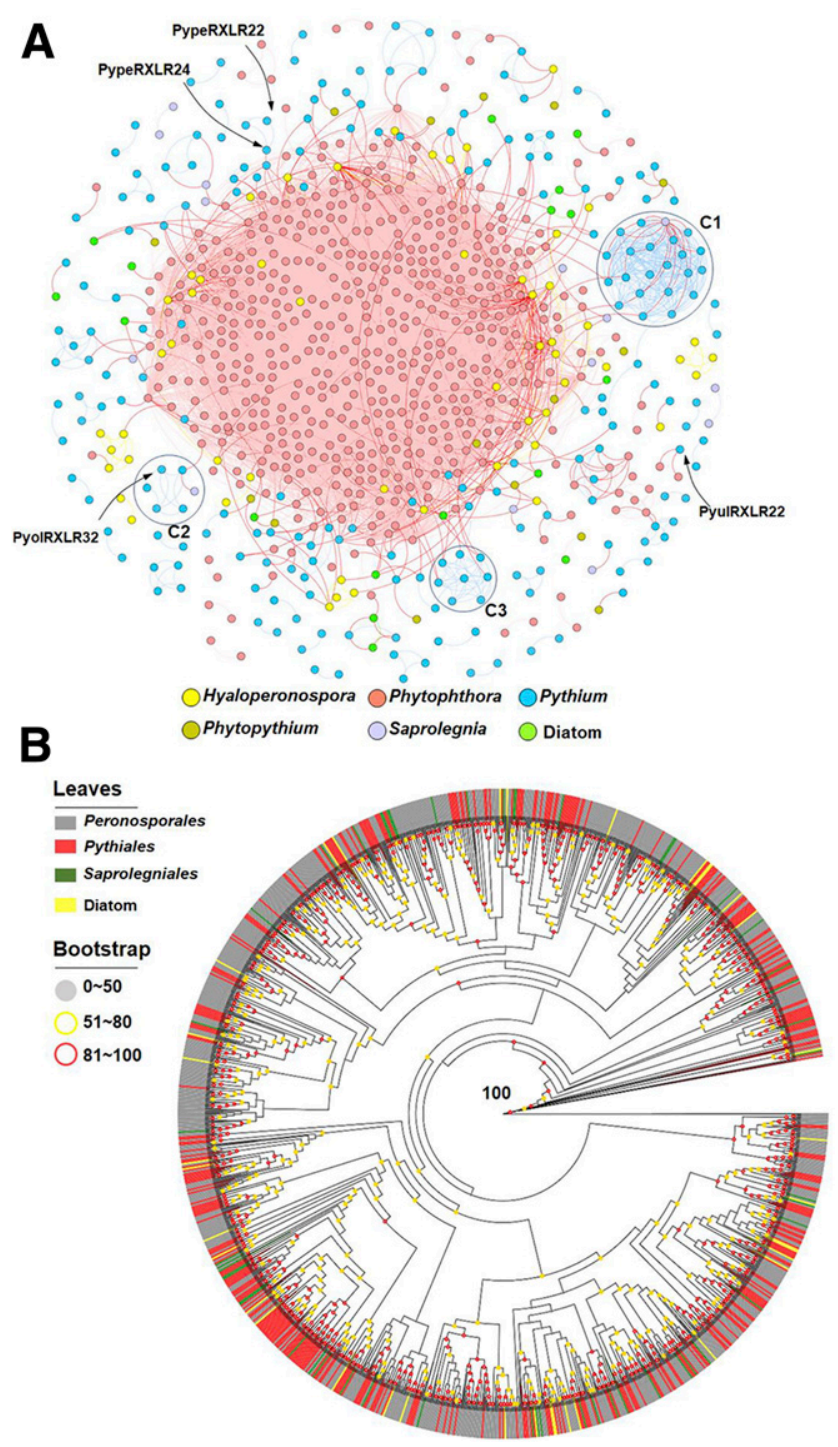

Fig. 2. The evolutionary patterns of oomycete RXLR effectors. A, The relatedness network of putative RXLR effectors. Each spot represents an RXLR effector. Similar RXLRs $(E$ value $<1)$ are joined by edges. Spot colors indicate genera. Three relatively independent clusters are marked as C1, C2, and C3. Almost all effectors in these clusters are from Pythium spp. The four RXLRs with effector activities verified in this study are labeled using arrows. B, Maximum-likelihood phylogenetic tree of the RXLRdEER motifs in RXLR effectors. Gray, yellow, and red circles in the nodes indicate bootstrap values of 0 to 50,51 to 80 , and 80 to 100 , respectively. Tree leaves are colored based on the families of their respective species. 
genes $(0.92 \mathrm{~kb})$ (Fig. 3C). Both observations are similar to the results of a previous report (Haas et al. 2009)

Similar gene location preferences were detected for Pythium $R X L R s$ in our study. At both the $5^{\prime}$ and $3^{\prime}$ ends, the average intergenic distances of the $R X L R$ genes were longer than the average intergenic distances of the complete gene sets of all nine examined Pythium species (Fig. 3C). For the $5^{\prime}$ and the $3^{\prime}$ ends, this difference was statistically significant $(P<0.05$, Student's $t$ test) in seven and three Pythium species, respectively (Fig. 3C). These results indicate that Pythium RXLRs are predominantly located in gene-sparse regions, which is similar to the case of Phytophthora RXLR genes.

\section{Genome rearrangement contributes to the emergence of novel $R X L R$ genes in $P$. guiyangense.}

The RXLR repertoire in $P$. guiyangense is larger than that in all other Pythium species examined (Fig. 1B). Our previous synteny analysis showed that $P$. guiyangense has a hybrid genome derived from two distinct parental species, which leads to a nearly twofold expansion of its predicted genes when compared with other Pythium species. Consequently, most homologous gene pairs in $P$. guiyangense show high degrees of collinearity (Shen et al. 2019). However, we only found four $R X L R$ genes from different scaffolds showing collinearity, indicating that additional mechanisms may have contributed to the expansion of $R X L R$ genes in $P$. guiyangense. We noticed that 29 PyguRXLR genes formed several clusters $(<40 \mathrm{~kb}$ in size), with each cluster located in the rearrangement region of the same contig. A similar phenomenon was not observed in other Pythium species (Supplementary Fig. S2). For example, PyguRXLR6/7/8 (Fig. 4A) and PyguRXLR32/33/34 (Fig. 4B) were clustered in the genome rearrangement regions of contigs 2 and 9, respectively. Furthermore, 22 clustered RXLRs showed high similarities in the $\mathrm{N}$-terminal region but had less conserved or even highly divergent C-termini within each cluster. For example, PyguRXLR6, PyguRXLR7, and PyguRXLR8 shared a conserved $\mathrm{N}$ terminal but had highly divergent $\mathrm{C}$ termini (Fig. 4C). A similar pattern was observed in PyguRXLR32 and PyguRXLR33 versus PyguRXLR34 (Fig. 4D). Taken together, these results suggest that both gene

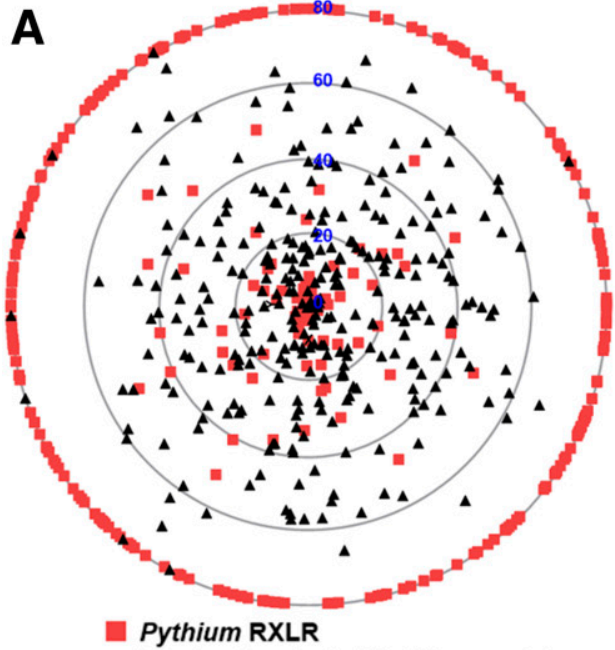

$\Delta$ Randomly selected Pythium proteins

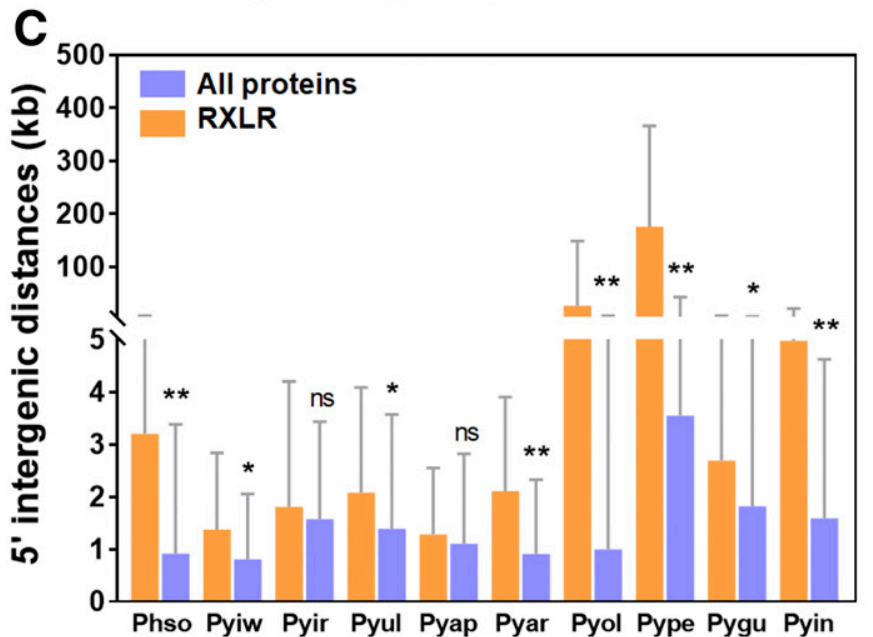

B

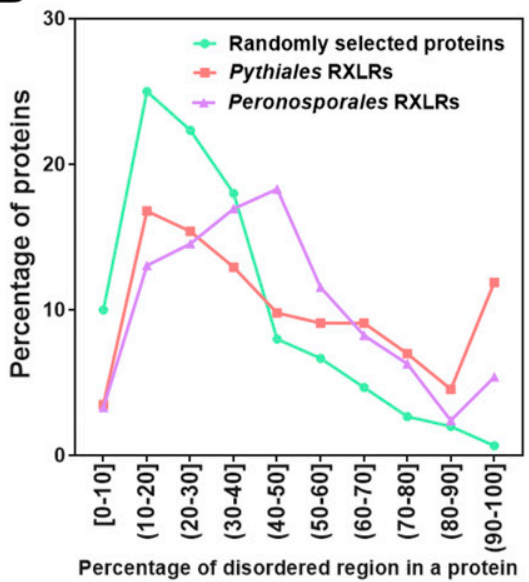

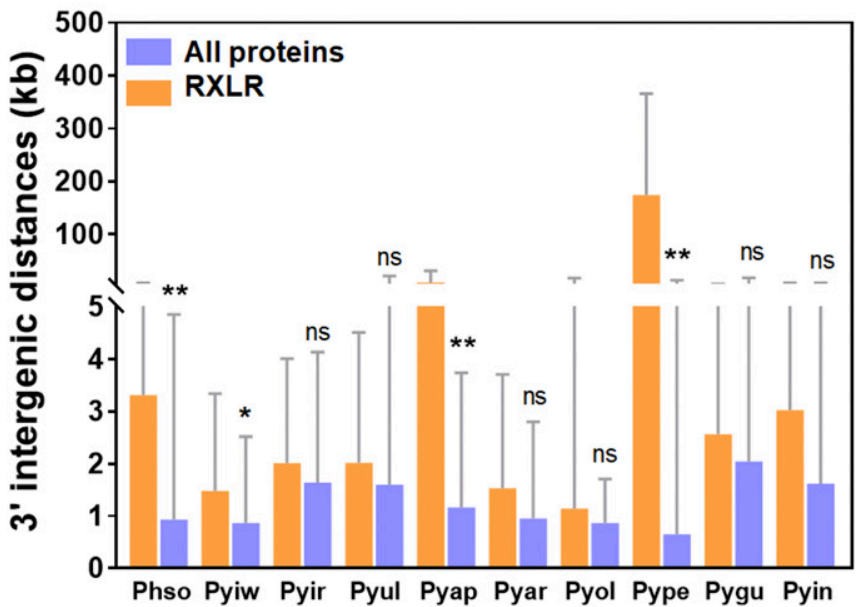

Fig. 3. Evolutionary features of Pythium RXLR effectors. A, Sequence divergence of Pythium RXLR effectors. Pythium RXLRs were compared against 300 randomly selected Pythium proteins to determine the sequence identities of their closest ortholog pairs within the Pythium genus. Radiuses ranging from 0 (center) to 80 (outer circle) represent $100 \%$ to $20 \%$ (or less) sequence identities, respectively. Proteins with the same identity level are randomly distributed along their corresponding circle. B, Disorder content in Peronosporales and Pythiales RXLRs. The line plot shows the percentages of proteins containing different percentages of disordered regions. The bar plot shows the total disorder percentages in Peronosporales RXLRs, Pythiales RXLRs, and randomly selected proteins. RSP = randomly selected proteins, PyRXLR = Pythiales RXLRs, and PerRXLR = Peronosporales RXLRs. C, 5' and 3' intergenic distances of Phytophthora sojae and Pythium RXLRs. The two bar plots show $5^{\prime}$ (left) and $3^{\prime}$ (right) intergenic distances of the indicated RXLR genes. (one asterisk [*] indicates $P<0.05$ and two [**] $P<0.001$, Student's $t$ test $)$. Phso $=$ Phytophthora sojae, Pyiw $=P$. iwayamai, Pyir $=P$. irregulare, Pyul $=P$. ultimum, Pyap $=P$. aphanidermatum, Pyar $=P$. arrhenomanes, Pyol $=P$. oligandrum, Pype $=P$. periplocum, Pygu $=P$. guiyangense, Pyin $=P$. insidiosum . 
duplications and genome rearrangements contributed to the expansion and emergence of novel $R X L R$ genes in $P$. guiyangense. Ultimately, the roles of RXLR effectors in $P$. guiyangense-mosquito interaction will be interesting for future study.

\section{Most predicted $P$. ultimum $R X L R$ genes are truly transcribed genes.}

To further elucidate whether the predicted Pythium RXLRs were truly transcribed genes, an RNA-seq analysis was carried out to examine the transcript accumulation of 40 RXLR candidates in $P$. ultimum during the mycelium stage and the stages at $3,6,12,24$, and $36 \mathrm{~h}$ after host infection. As one of the most important oomycetous plant pathogens with an available highquality assembled genome sequence (Lévesque et al. 2010; Kamoun et al. 2015), P. ultimum was selected as the investigation target. Except for two candidates (PyulRXLR25 and PyulRXLR26) whose RPKM (reads per kilobase transcript length per million reads mapped) values were consistently $<1$ at all stages, transcripts of the remaining 38 predicted $R X L R$ genes were detected at one or more stages (Fig. 5A), suggesting that most of the $P$. ultimum $R X L R$ genes predicted in our study were truly transcribed genes.

P. ultimum $R X L R$ genes showed stage-specific expression patterns. They were assigned to four gene expression clusters (Fig. 5A) via hierarchical clustering. $\mathrm{C} 1$ contained two putative pseudogenes and five $R X L R$ genes exhibiting zero to low expression. Despite their low transcript accumulation, all $R X L R$ genes in this cluster showed elevated expression during early infection stages. The 14 RXLR genes in C2 exhibited elevated transcript accumulation in both the mycelium and late-infection stages. The expression of $11 \mathrm{C} 3 R X L R$ genes was largely constant across all stages, with slightly more transcripts detected 3 to $6 \mathrm{~h}$ postinfection. The eight cluster 4 (C4) RXLR genes showed a similar expression pattern as the $R X L R$ genes in
$\mathrm{C} 2$ but with much higher RPKM values. These results revealed major transcription shifts of PyulRXLR genes at the mycelium and different host-infection stages.

\section{PyulRXLR22 induces cell death in Nicotiana benthamiana.}

Phytophthora RXLRs suppress PAMP-induced plant cell death. Furthermore, their ectopic expression can trigger cell death in plants (Wang et al. 2011). To evaluate the effector activity of predicted PyulRXLRs, we selected four candidates (PyulRXLR3, PyulRXLR4, PyulRXLR10, and PyulRXLR22, two candidates from $\mathrm{C} 1$ and two candidates from $\mathrm{C} 4$ ) for functional characterization (Fig. 5A). When coexpressed with INF1 (Kanneganti et al. 2006) in $N$. benthamiana leaves, none of these four RXLRs suppressed cell death triggered by the $P$. infestans PAMP INF1 (Supplementary Fig S3). In the evaluation of their ability to trigger host cell death by ectopic expression, only PyulRXLR22 induced dramatic cell death in $N$. benthamiana leaves (Fig. 5B). PyulRXLR22 expression was highly upregulated at the late infection stages (Fig. 5A). Fused with a green fluorescent protein (GFP) tag at the N-terminal region, the four PyulRXLRs were transiently expressed in $N$. benthamiana epidermal cells to reveal their subcellular localizations. PyulRXLR22 was located in the endoplasmic reticulum (ER), plasma membrane, and nucleus (Fig. 5C). In contrast, PyulRXLR3, PyulRXLR4, and PyulRXLR10 were found in the plasma membrane and the nucleus but not in the ER (Fig. 5C). Bioinformatic analysis showed that PyulRXLR22 had two homologs in Phytophthora ramorum (BLASTP E value $<1$ ) (Fig. 2A). The demonstrated effector activity makes PyulRXLR22 and its homologs promising targets for further investigation.

\section{RXLRs from biocontrol Pythium species induce plant defense in $N$. benthamiana.}

$P$. oligandrum and $P$. periplocum are two unique Pythium species that are widely used for controlling soilborne plant
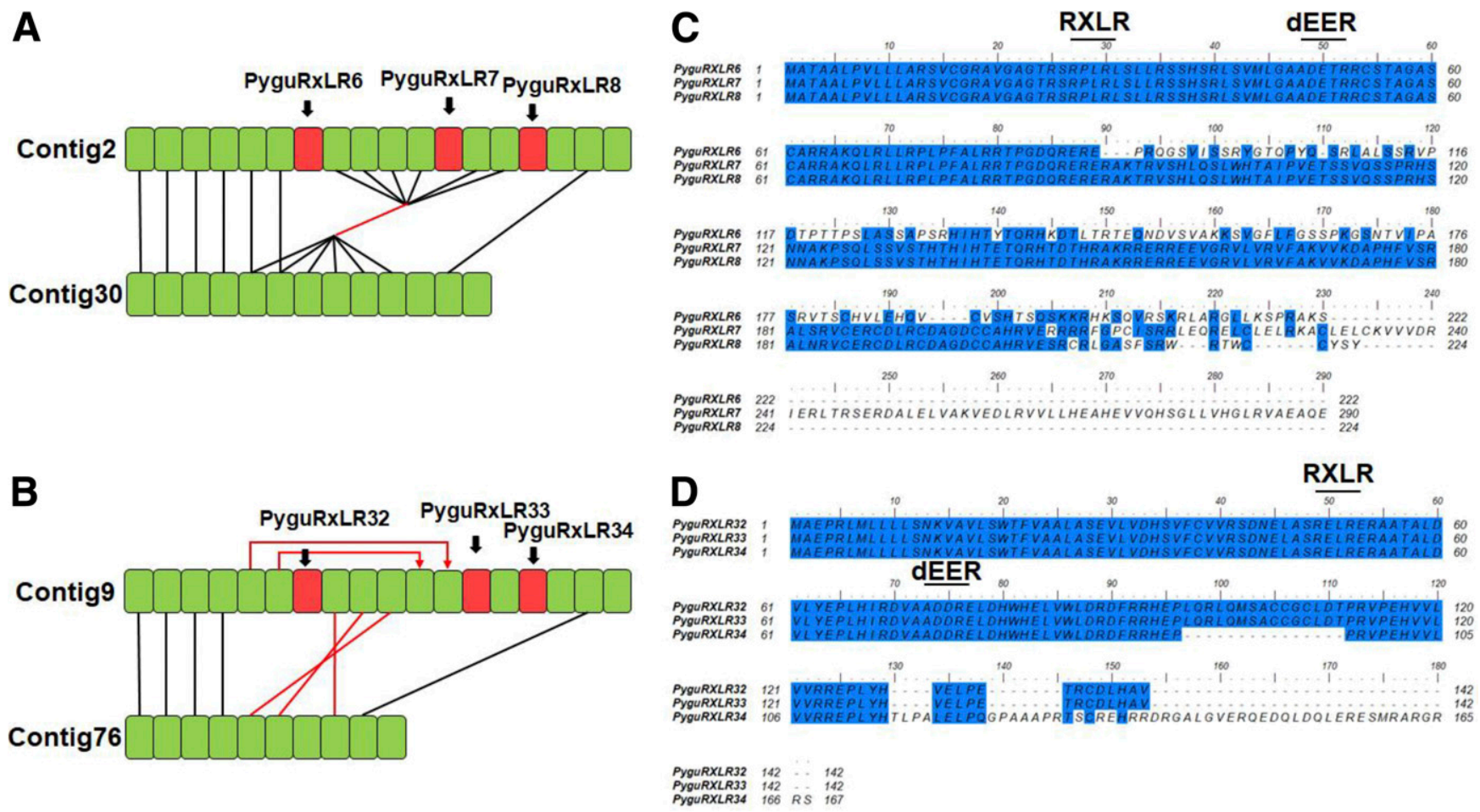

Fig. 4. Synteny analysis and protein sequence alignments of clustered RXLRs in Pythium guiyangense. $\mathbf{A}$ and $\mathbf{B}$, Synteny analysis of clustered $P$. guiyangense RXLRs. Red blocks indicate the clustered PyguRXLR genes described in the text. Green blocks indicate genes flanking these PyguRXLRs. Homologous genes with similar and opposite genome orientations are joined with black and red edges, respectively. C and D, Protein sequence alignments of two RXLR clusters. Identical or similar residues are colored in blue. The RXLR-dEER motifs are labeled in the alignments. 
diseases. These species can infect pathogens and induce plant defense reactions (Benhamou et al. 1997; Paul 1999; Takenaka et al. 2003). To elucidate whether the RXLRs of $P$. oligandrum and $P$. periplocum participate in this biocontrol process, all 73 RXLRs of the two species were cloned and were expressed in $N$. benthamiana leaves individually to test their ability to trigger cell death. PyolRXLR32, PypeRXLR22, and PypeRXLR24 triggered cell death 7 days postinfiltration (Fig. 6A), indicating that the effectors may confer plant defense-inducing activity. All other 70 RXLRs lacked this ability. PyolRXLR32 was located in the plasma membrane and the nucleus. Both PypeRXLR22 and PypeRXLR24 were located in plasma and nuclear membranes (Supplementary Fig. S4).
To investigate whether the three RXLR effectors can induce plant defenses, we infiltrated $N$. benthamiana leaves with Agrobacterium tumefaciens harboring GFP or the indicated $R X L R$ fusion construct and then inoculated the leaves with Phytophthora capsici. Compared with the GFP control, both PyolRXLR32 and PypeRXLR22 significantly reduced the lesion area caused by Phytophthora capsici, whereas PypeRXLR24 did not have a noticeable effect on lesion control (Fig. 6B and C).

Reactive oxygen species (ROS) play a central role in plant immunity and ROS bursts are a defense-response indicator (Qi et al. 2017). Our diaminobenzidine (DAB)-staining assay showed that, compared with the GFP control, ectopic

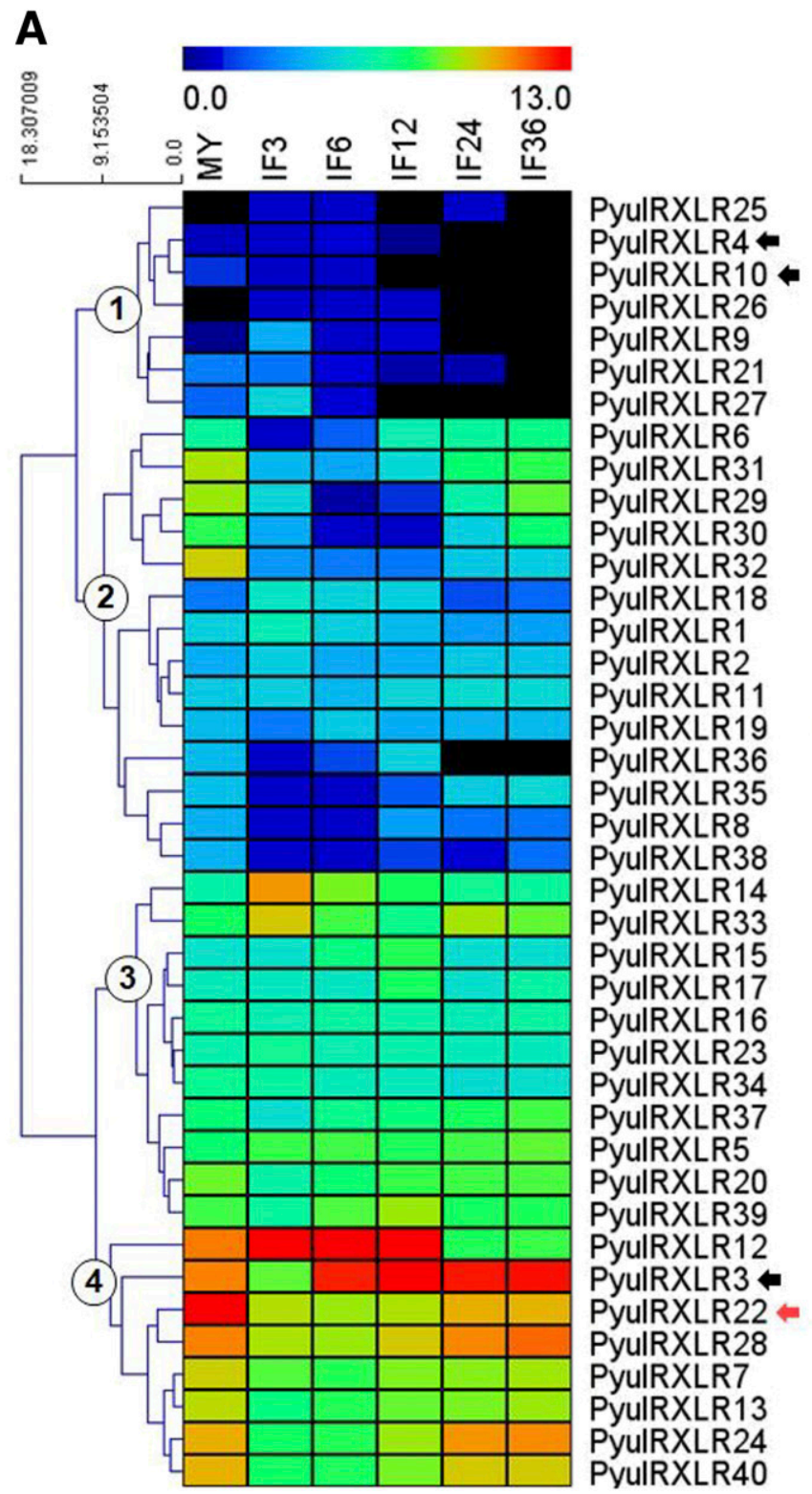

B
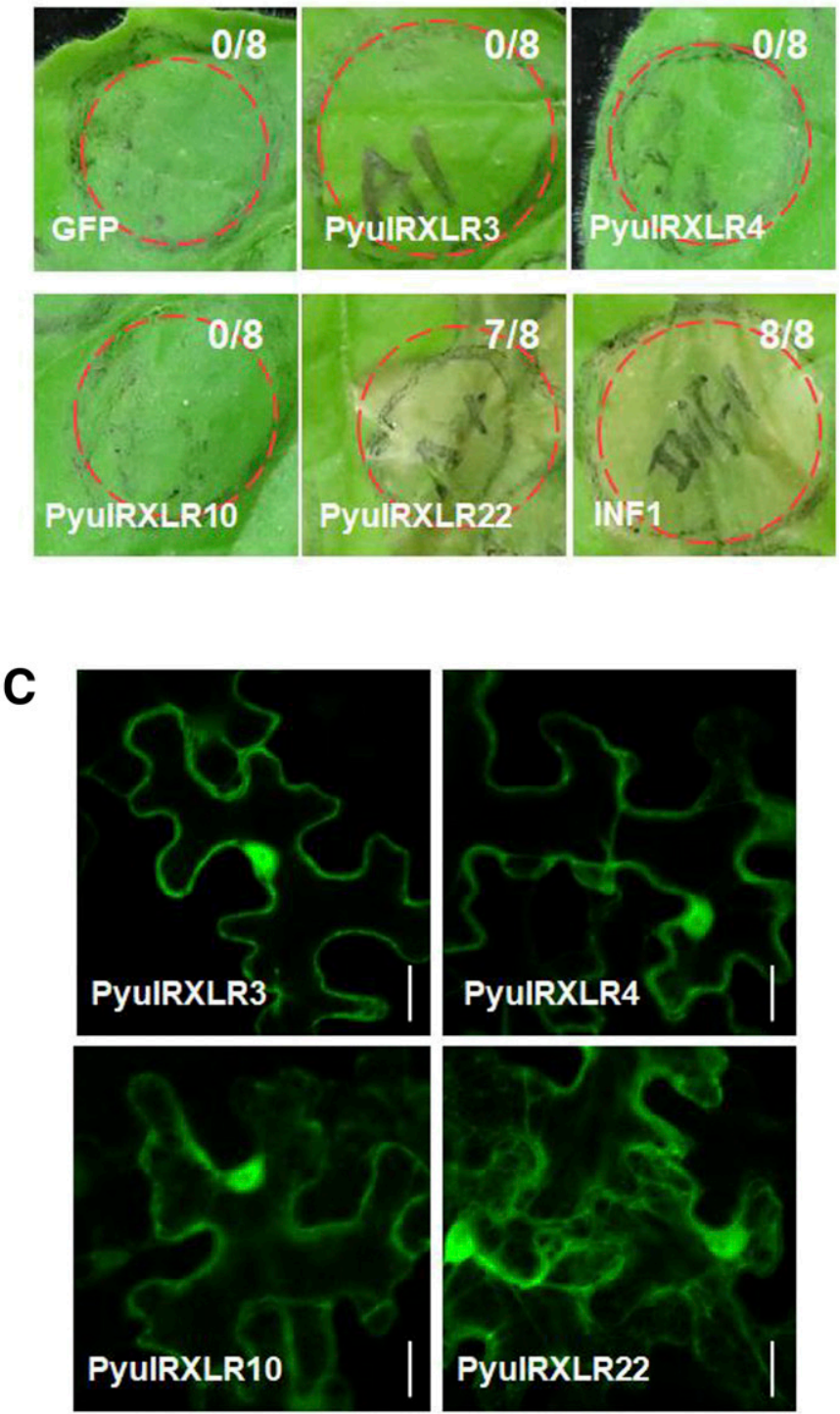

Fig. 5. Transcription patterns of Pythium ultimum RXLR genes and the effector activity of PyulRXLR22. A, Transcription patterns of $P$. ultimum RXLR candidates. The heat map shows gene transcription patterns at the mycelial (MY) stage and 3, 6, 12, 24, and 36 h postinoculation (hpi) of soybean leaves. Colored bars indicate the $\log _{2}$ of gene RPKM values (reads per kilobase transcript length per million reads mapped), ranging from dark blue (0) to red (13). Black bars indicate there was no expression detected. RXLRs selected for the effector activity assay are marked with arrows, and red arrows indicate the ability to induce cell death in Nicotiana benthamiana. Based on transcript accumulation levels and patterns, the $P$. ultimum RXLR genes are divided into four clusters, using hierarchical clustering methods and MeV software. Clusters are marked with circled numbers (1 to 4). B, PyulRXLR22 induced cell death in $N$. benthamiana. $N$. benthamiana leaves were transformed with the indicated constructs by agroinfiltration. Dashed circles indicate infiltration sites. The ratios indicate the number of sites with necrotic lesions versus the total number of infiltration sites. PyulRXLR3, PyulRXLR4, and PyulRXLR10 did not induce cell death. Green fluorescent protein and INF1 were used as negative and positive controls, respectively. C, Subcellular localization of PyulRXLRs. Green fluorescence indicates the localizations of PyulRXLRs in N. benthamiana epidermal cells. Photographs were taken at 48 hpi. Bar $=20 \mu \mathrm{m}$. 
expression of any of the three RXLRs induced an ROS burst in $N$. benthamiana leaves (Fig. 6D). Furthermore, all three RXLRs enhanced the ROS burst triggered by Phytophthora capsici inoculation (Fig. 6E).

Interestingly, PyolRXLR32 is conserved both intragenusly and intergenusly (Supplementary Fig. S5). Its P. infestans homolog (BLASTP E value $=2 \mathrm{e}-115)$, previously reported as SFI4 (suppressor of early Flg22-induced immune response 4), can inhibit host immunity and promote infection (Zheng et al. 2014); this role is opposite to the positive role of PyolRXLR32 in triggering cell death and defense responses. Likewise, although PypeRXLR21, PypeRXLR22, and PypeRXLR24 share high sequence similarity (Supplementary Fig. S6), PypeRXLR21 cannot trigger host cell death as PypeRXLR22, and PypeRXLR24 did (Fig. 6A). These results indicate that slight sequence differences may lead to diverse or even contrary functions of homologous RXLR effectors.

\section{DISCUSSION}

In this study, we performed a de novo identification of RXLR effector genes from the genomes of nine Pythium species and analyzed their evolutionary features. Selected Pythium RXLR effectors were functionally verified. Despite the modified prediction method we adopted, RXLRs were found in a wide range of oomycetes, including the studied Pythium species, but were almost absent outside stramenopiles species. Our phylogenetic analysis indicates RXLRs have a common ancestor, with all oomycetous RXLRs clustered into a single superfamily. Pythium and Phytophthora RXLR genes share several features, including a rapid evolution, high disorder content and the tendency to be located in gene-sparse regions. In particular, the RXLR reservoir of $P$. guiyangense, due to frequent gene duplication and genome rearrangement events, is much larger than that of other Pythium species. Using P. ultimum as a model for plant pathogens, most of its predicted $R X L R$ genes were demonstrated to be truly transcribed genes clustered into four distinct expression patterns. The effector activity of PyulRXLR22 was functionally verified in this study. Finally, we identified three functional RXLR effectors from two biocontrol Pythium species.

Although no Pythium RXLRs have been identified before (Lévesque et al. 2010; Adhikari et al. 2013), there have been clues indicating their existence. Several RXLR effectors have been experimentally validated in species phylogenetically close to Pythium, including Albugo candida, Albugo laibachii, and Saprolegnia parasitica (Kemen et al. 2011; Links et al. 2011; Wawra et al. 2012). The necrotrophic infection type of Pythium pathogens also matches the observations that many RXLR effectors induce necrosis. Largely due to the stringent definition of the dEER motif, existing genome annotation models may be inadequate for RXLR gene prediction in Pythium species. Hence, we developed a modified regex model to allow the search for degenerate dEER motifs. Previously, reported
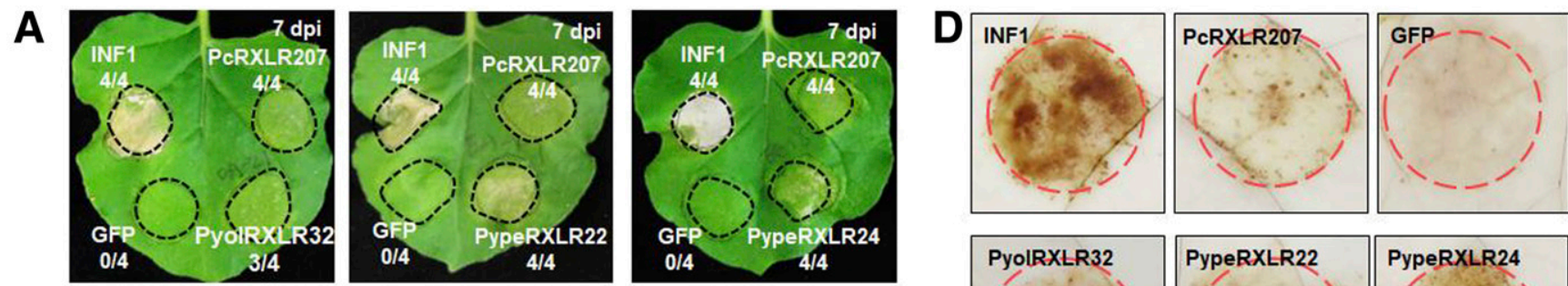

B
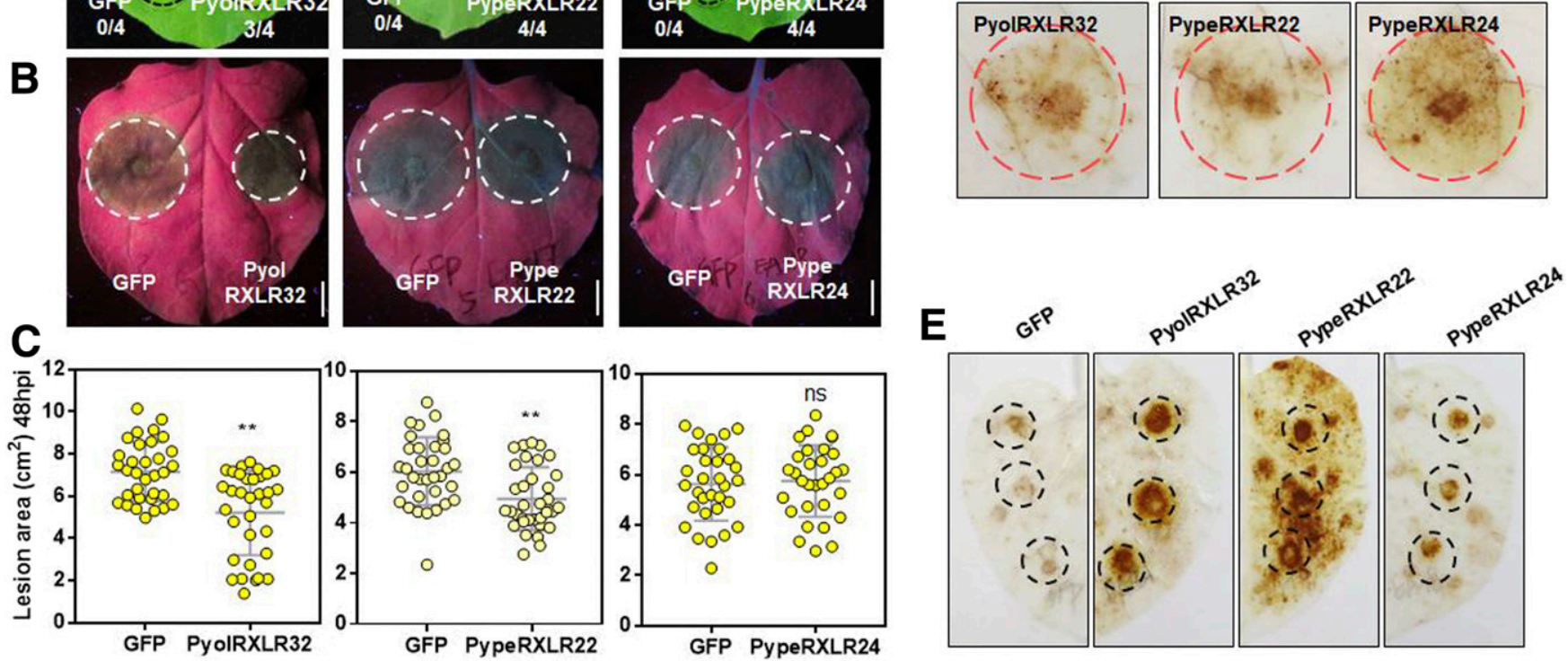

Fig. 6. RXLRs from Pythium oligandrum and P. periplocum induce plant defense responses. A, Expression of PyolRXLR32, PypeRXLR22, or PypeRXLR24 induced cell death in Nicotiana benthamiana leaves. $N$. benthamiana leaves were transformed with the indicated constructs by agroinfiltration. Dashed circles indicate infiltration sites, and the ratios indicate the number of sites with necrotic lesions versus the total number of infiltration sites. INF1 and the RXLR effector RXLR207 from Phytophthora capsici were used as positive controls. An empty vector expressing green fluorescent protein (GFP) was used as a negative control. The same controls were also used in the $\mathrm{H}_{2} \mathrm{O}_{2}$ accumulation assay. B and $\mathbf{C}$, Phytophthora capsici infection was reduced by PyolRXLR32 and PypeRXLR22 but not by PypeRXLR24. At $24 \mathrm{~h}$ after infiltration, equal amounts of mycelium were inoculated onto each infiltrated area expressing PyolRXLR32, PypeRXLR22, or PypeRXLR24. Photographs were taken under UV light at $48 \mathrm{~h}$ postinoculation (hpi), and the lesion areas were measured at the same time. Lesion area data shown in the dot plots were collected from three biological replicates. At least five leaves were inoculated for each replicate (two asterisks [**] indicate $P<0.001$, Student's $t$ test). Bar $=1 \mathrm{~cm} . \mathbf{D}, \mathrm{H}_{2} \mathrm{O}_{2}$ accumulation in $N$. benthamiana leaves expressing PyolRXLR32, PypeRXLR22, or PypeRXLR24. Diaminobenzidine (DAB) staining was performed 48 hpi. Red dashed circles indicate infiltration sites. E, $\mathrm{H}_{2} \mathrm{O}_{2}$ accumulation in Phytophthora capsici-inoculated N. benthamiana leaves expressing PyolRXLR32, PypeRXLR22, or PypeRXLR24. Phytophthora capsici was inoculated 24 h after infiltration. DAB staining was performed at 12 hpi. Black dashed circles indicate inoculation sites. 
effectors were adopted as references, and all six ORFs were retrieved from the whole genomes. To reduce false-positive rates, we omitted the BLASTP step following the RXLR search. By adopting our modified regex model, we predicted 359 new RXLR proteins in nine Pythium species and re-identified RXLRs from $H$. arabidopsidis, Phytophthora ramorum, and Phytophthora sojae. The high accuracy of our new model was demonstrated by the observation that very few RXLRs were predicted outside the stramenopiles and that all re-identified RXLRs were subsets of previously known RXLRs. Notably, our detection of RXLR-like proteins in diatoms suggests oomycetous RXLRs originated from an early ancestor of the stramenopile lineage. Pythium and other oomycetous RXLRs formed a superfamily in our phylogenetic analysis, which also supports the common ancestor hypothesis of RXLR evolution.

Despite the high divergence of RXLR sequences, the oomycetous RXLRs identified in our study were similar enough to form a large relatedness network, with Phytophthora RXLRs exhibiting the most overall sequence similarities. There were also RXLR clusters predominantly associated with Pythium or Hyaloperonospora species, suggesting these effectors evolved independently.

Phytophthora and Pythium RXLRs share several common features. Phytophthora RXLR effectors promote virulence by manipulating host defense processes. Thus, they undergo rapid sequence evolution to escape the surveillance of the plant immune system. In our study, this fast evolution pattern was also observed in Pythium RXLRs, which indicates their participation in host pathogenesis. As a consequence of effector evolution, there are abundant disorder regions in Phytophthora RXLRs (Shen et al. 2017). These disordered regions are even more prevalent in Pythium RXLRs. Phytophthora genomes feature the so-called 'two-speed' structure of gene-dense and gene-sparse regions (Raffaele and Kamoun 2012), and RXLR genes are enriched in the more dynamic gene-sparse regions. Gene-sparse regions are the heat sites of genome rearrangement and tend to accelerate pathogen evolution (Dong et al. 2015). In Pythium species, we also found that both the $5^{\prime}$ and $3^{\prime}$ average intergenic distances of $R X L R$ genes were significantly longer than the whole-genome averages, which demonstrates Pythium $R X L R s$ also tend to be located in gene-sparse regions.

Due to their highly divergent C termini, few RXLR paralogs were found in the Pythium genus, except for $P$. guiyangense. We characterized the $P$. guiyangense genome as a hybrid and identified a large set of RXLR genes. P. guiyangense RXLRs share low degrees of synteny with PyguRXLR paralogs, which are often clustered in the same contig and located in genome rearrangement regions. Furthermore, physically close paralogous pairs generally share a conserved $\mathrm{N}$ terminal but have lessconserved or even highly divergent $\mathrm{C}$-termini. Our results indicate that recent gene duplication and genome rearrangement events shaped the evolution of $P$. guiyangense RXLRs. Previous research suggests that the duplications of genes encoding virulence-associated effectors facilitate pathogen adjustment toward host jumps (Raffaele et al. 2010). In the case of $P$. guiyangense, the detected duplication and rearrangement events may have generated novel $R X L R$ genes helping the adaptation of the species against insects. RXLR genes also cluster closely ( $<100 \mathrm{~kb})$ in Phytophthora ramorum (Win et al. 2007), suggesting that the $R X L R$ gene cluster may be a common host adaptation strategy shared by oomycete species.

Our RNA-seq analysis of $P$. ultimum demonstrated that most predicted $R X L R$ genes were transcribed genes, which further verified the reliability of our redesigned RXLR annotation method. Furthermore, these $R X L R$ genes exhibit distinct expression patterns during infection. The expression stages of RXLRs are associated with their specific functions. In Phytophthora sojae, RXLRs that are induced early inhibit host cell death triggered by PAMPs, while necrosis is caused by late-induced RXLR effectors (Wang et al. 2011). Another Phytophthora pathogen, Phytophthora capsici, secretes an RXLR effector to induce host defense responses and cell death and trigger the biotrophto-necrotroph transition (Li et al. 2019). Since most Pythium pathogens are necrotrophic, their RXLRs may trigger host cell death instead of acting as cell-death repressors. Consistent with this expectation, none of our tested PyulRXLRs suppressed INF1-induced host cell death. Instead, ectopic expression of PyulRXLR22 triggered necrosis. The functional diversity of RXLRs in Phytophthora and Pythium species may result from their different nutrient acquisition strategies during infection.

$P$. oligandrum and $P$. periplocum are two biocontrol agents with largely unknown defense-inducing mechanisms. Previous reports suggest that plant defense may be induced by microbeassociated molecular patterns in these two Pythium species (Benhamou et al. 2012). In this study, we identified three RXLR effectors from $P$. oligandrum and $P$. periplocum and demonstrated the plant defense-induction ability of these RXLRs. This finding unveils the participation of cytoplasmic effectors in triggering host defense reactions. Since the $P$. oligandrum hyphae can penetrate into root tissues, the RXLR effectors of this species may be secreted to host cells via a similar mechanism as that detected in Phytophthora pathogens.

In conclusion, we identified RXLR effectors in Pythium species for the first time at the genome-wide scale. Their evolutionary features, sequence characteristics, and expression patterns were analyzed in detail. The effector activities of selected Pythium RXLRs, including their diversified functions in inducing cell death and host defense, were experimentally verified. This study expands our current understanding of oomycetous RXLR effectors to the Pythium genus. The resources generated in this work will facilitate future in-depth investigations on the interactions between the novel Pythium RXLRs and their diversified hosts.

\section{MATERIALS AND METHODS}

Data sets.

The genome sequences of Phytophthora ramorum and Phytophthora sojae (Tyler et al. 2006) were obtained from the Joint Genome Institute website. The genome sequences of H. arabidopsidis (Baxter et al. 2010), Phytophthora vexans (Adhikari et al. 2013), P. aphanidermatum (Adhikari et al. 2013), P. arrhenomanes (Adhikari et al. 2013), P. irregulare (Adhikari et al. 2013), P. iwayamai (Adhikari et al. 2013), $P$. oligandrum (Kushwaha et al. 2017), P. periplocum (Kushwaha et al. 2017), P. ultimum (Lévesque et al. 2010), $P$ insidiosum (Rujirawat et al. 2018), P. guiyangense (Shen et al. 2019), Saprolegnia parasitica (Jiang et al. 2013), Phaeodactylum tricornutum (Bowler et al. 2008), Thalassiosira pseudonana (Armbrust et al. 2004), Saccharomyces cerevisiae (Jacq et al. 1997), Sclerotinia sclerotiorum (Amselem et al. 2011), Ustilago maydis (Kämper et al. 2006), Puccinia graminis (Duplessis et al. 2011), Botrytis cinerea (Van Kan et al. 2017), Caenorhabditis elegans (C. elegans Sequencing Consortium 1998), Meloidogyne hapla (Opperman et al. 2008), Escherichia coli (Blattner et al. 1997), Erwinia amylovora (Smits et al. 2010) and 'Candidatus Liberibacter asiaticus' (Duan et al. 2009) were obtained from the National Center for Biotechnology Information. Detailed genomic information for all species is listed in Supplementary Table S7.

\section{Identification of RXLR effectors.}

For RXLR effector identification, all ORFs encoding proteins longer than 50 amino acids were retrieved. SPs were 
predicted using SignalP v3 with the criteria that cleavage sites had to be located between residues 10 and 40 and HMM probability $\geq 0.9$ (Bendtsen et al. 2004). TMs were predicted using TMHMM v2.0 (Krogh et al. 2001). Sequences containing SPs but lacking a TM were retained and were screened for RXLRs with a modified regex model described as SP. $\{1,40\}$ R.LR. $\{1,40\}([\mathrm{ED}] .[\mathrm{ED}][\mathrm{KR}] \mid[\mathrm{ED}][\mathrm{ED}] .\{0,3\} \mathrm{KR}])$. All matched protein sequences were predicted to be RXLR effectors. For redundant RXLRs caused by a set of alternative overlapping ORFs within the same reading frame, only the ORF encoding the longest RXLR was selected.

\section{Permutation test.}

A total of 90 after-SP residues of all sORFs were retrieved, permuted with random.shuffle() module in Python. Then the RXLR search using the method mentioned above was conducted in these permutated sequences. This process was conducted 100 times and the average number of RXLR effectors predicted in the permuted sequences was considered as the false-positive rate. The permutation code can be downloaded from GitHub.

\section{Phylogenetic analysis.}

For phylogenetic analysis, the SPs and C termini after the dEER motif were removed from the RXLR sequences. The truncated sequences were aligned using MUSCLE (Edgar 2004) and were then manually edited. Maximum-likelihood trees were constructed using IQ-TREE software with the -bb 1000 parameter (Nguyen et al. 2015). VT+F+R6 was selected as the best-fit model for this assay by using the ModelFinder tool in IQ-TREE. The phylogenetic tree was visualized using EvolView v3 (Subramanian et al. 2019).

\section{Disorder region prediction and synteny analysis.}

Disorder region prediction was performed by using ESpritz with the X-ray prediction type and the best-sw threshold (Walsh et al. 2012). Synteny analysis was conducted using MCScanX (Wang et al. 2012).

\section{Vector construction.}

For transient expression in $N$. benthamiana, PyulRXLR, PyolRXLR, and PypeRXLR genes (lacking the SP-encoding region) were amplified from their corresponding genomic DNA and were inserted into the pBinGFP2 vector (Song et al. 2015). The primers used for PCR amplification are listed in Supplementary Table S8.

\section{Plant materials and agroinfiltration.}

$N$. benthamiana plants were maintained in a greenhouse with an environmental temperature of $25^{\circ} \mathrm{C}$ under a 16-h light and 8-h dark photoperiod. The A. tumefaciens strain GV3101 had previously been stored in our lab. Before infiltration, A. tumefaciens clones harboring the indicated constructs were cultured at $28^{\circ} \mathrm{C}$ and $200 \mathrm{rpm}$ for $48 \mathrm{~h}$ to reach the appropriate concentration. The Agrobacterium cultures were then resuspended in $10 \mathrm{mM} \mathrm{MgCl}{ }_{2}$ to an appropriate optical density (OD). For the necrosis induction assay, A. tumefaciens cells were infiltrated into the 6-week-old leaves of $N$. benthamiana at a final $\mathrm{OD}_{600}$ of 0.2 for each construct. For the cell death suppression assay, A. tumefaciens cells expressing the indicated RXLR effectors $\left(\mathrm{OD}_{600}=0.3\right)$ were infiltrated into $N$. benthamiana leaves 1 day before the infiltration of $A$. tumefaciens expressing INF1 $\left(\mathrm{OD}_{600}=0.2\right)$. Symptom development was examined 7 days after infiltration.

Oomycete culture conditions and the inoculation assay.

The $P$. oligandrum CBS 530.74 and $P$. periplocum CBS 532.74 strains were provided by L. J. Grenville-Briggs at the
Swedish University of Agricultural Sciences and were stored at $25^{\circ} \mathrm{C}$ on $10 \%$ (vol/vol) V8 juice medium in the dark. P. ultimum and the Phytophthora capsici LT263 strain had previously been stored in our lab and were grown at $25^{\circ} \mathrm{C}$ on V8 medium in the dark. For Phytophthora capsici mycelium inoculation, 7-mm disks of 4-day growth medium were inoculated on $N$. benthamiana leaves $24 \mathrm{~h}$ after infiltration. Inoculated leaves were photographed at $48 \mathrm{~h}$ postinoculation (hpi) under UV light. Lesion areas were measured at the indicated timepoints. This assay was independently repeated at least three times. For the inoculation of $P$. ultimum, 4-mm plugs from the growing edge of a 2-day V8 agar culture were placed in the $N$. benthamiana leaves and the samples were harvested at the indicated timepoints.

\section{Transcriptome sequencing and bioinformatic analysis.}

For mycelium samples, $P$. ultimum mycelium growing in V8 agar culture for 2 days were harvested. $P$. ultimum samples at different infection stages $(3,6,12,24$, and $36 \mathrm{hpi})$ were harvested using a $5-\mathrm{cm}$ punch. Three biological replicates were performed and were used to produce an independent pool. The quality of total RNA was evaluated by an Agilent 2100 Bioanalyzer (Agilent Technologies, Santa Clara, CA, U.S.A.). Samples with $\mathrm{OD}_{260 / 230} \geq 1.8$ and $\mathrm{OD}_{260 / 280} \geq 1.8$ were used for RNA-seq. Raw reads were filtered using FastQC software (Babraham Bioinformatics website) to remove poor-quality reads and adapters. Sequences with a Phred score above 20 were considered clean reads. All clean reads were mapped to the $P$. ultimum reference genome, using Hisat2 with the parameters of -min-intronlen 30-max-intronlen 5000 -dta (Pertea et al. 2016). SAMtools was used to convert and sort SAM files ( $\mathrm{Li}$ et al. 2009). Based on the lengths of each gene and the counts of uniquely mapped reads, gene expression levels were normalized as RPKM using the Stringtie tool (Pertea et al. 2016). The RPKM values of PyRXLRs during different stages are shown in Supplementary Table S9. Heat maps and clustering (using hierarchical clustering methods) of gene expression patterns were performed using $\mathrm{MeV}$ software (Saeed et al. 2003).

\section{DAB staining.}

$N$. benthamiana leaves with ectopic expression of the indicated RXLR effectors were detached at $48 \mathrm{hpi}$ and were then stained with a $1-\mathrm{mg} / \mathrm{ml}$ DAB solution for $8 \mathrm{~h}$ in the dark. After destaining with ethanol, leaves were examined under light microscopy. Phytophthora capsici-inoculated $N$. benthamiana leaves were stained with a $1-\mathrm{mg} / \mathrm{ml}$ DAB solution for $8 \mathrm{~h}$ in the dark at $12 \mathrm{hpi}$ and were then destained with ethanol before photographing.

\section{ACKNOWLEDGMENTS}

We thank B. Tyler at Oregon State University for his useful suggestions and discussion.

\section{AUTHOR-RECOMMENDED INTERNET RESOURCES}

ESpritz: http://protein.bio.unipd.it/espritz

Babraham Bioinformatics FastQC software:

https://www.bioinformatics.babraham.ac.uk/index.html

GitHub permutation code: https://github.com/Gan-Ai/sequence-permutation The Joint Genome Institute website: http://genome.jgi-psf.org

National Center for Biotechnology Information: https://www.ncbi.nlm.nih.gov

\section{LITERATURE CITED}

Adhikari, B. N., Hamilton, J. P., Zerillo, M. M., Tisserat, N., Lévesque, C. A., and Buell, C. R. 2013. Comparative genomics reveals insight into virulence strategies of plant pathogenic oomycetes. PLoS One 8:e75072. 
Amselem, J., Cuomo, C. A., van Kan, J. A., Viaud, M., Benito, E. P. Couloux, A., Coutinho, P. M., de Vries, R. P., Dyer, P. S., Fillinger, S. Fournier, E., Gout, L., Hahn, M., Kohn, L., Lapalu, N., Plummer, K. M., Pradier, J. M., Quévillon, E., Sharon, A., Simon, A., ten Have, A., Tudzynski, B., Tudzynski, P., Wincker, P., Andrew, M., Anthouard, V., Beever, R. E., Beffa, R., Benoit, I., Bouzid, O., Brault, B., Chen, Z., Choquer, M., Collémare, J., Cotton, P., Danchin, E. G., Da Silva, C., Gautier, A., Giraud, C., Giraud, T., Gonzalez, C., Grossetete, S. Güldener, U., Henrissat, B., Howlett, B. J., Kodira, C., Kretschmer, M., Lappartient, A., Leroch, M., Levis, C., Mauceli, E., Neuvéglise, C., Oeser, B., Pearson, M., Poulain, J., Poussereau, N., Quesneville, H., Rascle, C., Schumacher, J., Ségurens, B., Sexton, A., Silva, E., Sirven, C., Soanes, D. M., Talbot, N. J., Templeton, M., Yandava, C., Yarden, O. Zeng, Q., Rollins, J. A., Lebrun, M. H., and Dickman, M. 2011. Genomic analysis of the necrotrophic fungal pathogens Sclerotinia sclerotiorum and Botrytis cinerea. PLoS Genet. 7:e1002230.

Anderson, R. G., Deb, D., Fedkenheuer, K., and McDowell, J. M. 2015 Recent progress in rxlr effector research. Mol. Plant-Microbe Interact. 28:1063-1072.

Armbrust, E. V., Berges, J. A., Bowler, C., Green, B. R., Martinez, D., Putnam, N. H., Zhou, S., Allen, A. E., Apt, K. E., Bechner, M., Brzezinski, M. A., Chaal, B. K., Chiovitti, A., Davis, A. K., Demarest, M. S., Detter, J. C., Glavina, T., Goodstein, D., Hadi, M. Z., Hellsten, U., Hildebrand, M., Jenkins, B. D., Jurka, J., Kapitonov, V. V., Kröger, N., Lau, W. W., Lane, T. W., Larimer, F. W., Lippmeier, J. C., Lucas, S., Medina, M., Montsant, A., Obornik, M., Parker, M. S., Palenik, B., Pazour, G. J., Richardson, P. M., Rynearson, T. A., Saito, M. A., Schwartz, D. C., Thamatrakoln, K., Valentin, K., Vardi, A., Wilkerson, F. P., and Rokhsar, D. S. 2004. The genome of the diatom Thalassiosira pseudonana: Ecology, evolution, and metabolism. Science 306:79-86.

Baxter, L., Tripathy, S., Ishaque, N., Boot, N., Cabral, A., Kemen, E., Thines, M., Ah-Fong, A., Anderson, R., Badejoko, W., Bittner-Eddy, P., Boore, J. L., Chibucos, M. C., Coates, M., Dehal, P., Delehaunty, K., Dong, S., Downton, P., Dumas, B., Fabro, G., Fronick, C., Fuerstenberg, S. I., Fulton, L., Gaulin, E., Govers, F., Hughes, L., Humphray, S., Jiang, R. H. Y., Judelson, H., Kamoun, S., Kyung, K., Meijer, H., Minx, P., Morris, P., Nelson, J., Phuntumart, V., Qutob, D., Rehmany, A., RougonCardoso, A., Ryden, P., Torto-Alalibo, T., Studholme, D., Wang, Y., Win, J., Wood, J., Clifton, S. W., Rogers, J., Van den Ackerveken, G., Jones, J. D. G., McDowell, J. M., Beynon, J., and Tyler, B. M. 2010. Signatures of adaptation to obligate biotrophy in the Hyaloperonospora arabidopsidis genome. Science 330:1549-1551.

Bendtsen, J. D., Nielsen, H., von Heijne, G., and Brunak, S. 2004. Improved prediction of signal peptides: SignalP 3.0. J. Mol. Biol. 340:783-795.

Benhamou, N., le Floch, G., Vallance, J., Gerbore, J., Grizard, D., and Rey, P. 2012. Pythium oligandrum: An example of opportunistic success. Microbiology 158:2679-2694.

Benhamou, N., Rey, P., Chérif, M., Hockenhull, J., and Tirilly, Y. 1997. Treatment with the mycoparasite Pythium oligandrum triggers induction of defense-related reactions in tomato roots when challenged with Fusarium oxysporum f. sp. radicis-lycopersici. Phytopathology 87:108-122.

Blattner, F. R., Plunkett, G., 3rd, Bloch, C. A., Perna, N. T., Burland, V., Riley, M., Collado-Vides, J., Glasner, J. D., Rode, C. K., Mayhew, G. F., Gregor, J., Davis, N. W., Kirkpatrick, H. A., Goeden, M. A., Rose, D. J., Mau, B., and Shao, Y. 1997. The complete genome sequence of Escherichia coli K-12. Science 277:1453-1462.

Bowler, C., Allen, A. E., Badger, J. H., Grimwood, J., Jabbari, K., Kuo, A., Maheswari, U., Martens, C., Maumus, F., Otillar, R. P., Rayko, E., Salamov, A., Vandepoele, K., Beszteri, B., Gruber, A., Heijde, M., Katinka, M., Mock, T., Valentin, K., Verret, F., Berges, J. A., Brownlee, C., Cadoret, J. P., Chiovitti, A., Choi, C. J., Coesel, S., De Martino, A., Detter, J. C., Durkin, C., Falciatore, A., Fournet, J., Haruta, M., Huysman, M. J., Jenkins, B. D., Jiroutova, K., Jorgensen, R. E., Joubert, Y., Kaplan, A., Kröger, N., Kroth, P. G., La Roche, J., Lindquist, E., Lommer, M., Martin-Jézéquel, V., Lopez, P. J., Lucas, S., Mangogna, M., McGinnis, K., Medlin, L. K., Montsant, A., Oudot-Le Secq, M. P., Napoli, C., Obornik, M., Parker, M. S., Petit, J. L., Porcel, B. M., Poulsen, N., Robison, M., Rychlewski, L., Rynearson, T. A., Schmutz, J., Shapiro, H., Siaut, M., Stanley, M., Sussman, M. R., Taylor, A. R., Vardi, A., von Dassow, P., Vyverman, W., Willis, A., Wyrwicz, L. S., Rokhsar, D. S., Weissenbach, J., Armbrust, E. V., Green, B. R., Van de Peer, Y., and Grigoriev, I. V. 2008. The Phaeodactylum genome reveals the evolutionary history of diatom genomes. Nature 456:239-244.

C. elegans Sequencing Consortium. 1998. Genome sequence of the nematode $C$. elegans: A platform for investigating biology. Science 282:2012-2018.

Deb, D., Anderson, R. G., How-Yew-Kin, T., Tyler, B. M., and McDowell, J. M. 2018. Conserved RxLR effectors from oomycetes
Hyaloperonospora arabidopsidis and Phytophthora sojae suppress PAMP- and effector-triggered immunity in diverse plants. Mol. PlantMicrobe Interact. 31:374-385.

Dong, S., Raffaele, S., and Kamoun, S. 2015. The two-speed genomes of filamentous pathogens: Waltz with plants. Curr. Opin. Genet. Dev. 35: 57-65.

Dou, D., and Zhou, J. M. 2012. Phytopathogen effectors subverting host immunity: Different foes, similar battleground. Cell Host Microbe 12: 484-495.

Duan, Y., Zhou, L., Hall, D. G., Li, W., Doddapaneni, H., Lin, H., Liu, L., Vahling, C. M., Gabriel, D. W., Williams, K. P., Dickerman, A., Sun, Y., and Gottwald, T. 2009. Complete genome sequence of citrus huanglongbing bacterium, 'Candidatus Liberibacter asiaticus' obtained through metagenomics. Mol. Plant-Microbe Interact. 22:1011-1020.

Duplessis, S., Cuomo, C. A., Lin, Y. C., Aerts, A., Tisserant, E., VeneaultFourrey, C., Joly, D. L., Hacquard, S., Amselem, J., Cantarel, B. L., Chiu, R., Coutinho, P. M., Feau, N., Field, M., Frey, P., Gelhaye, E., Goldberg, J., Grabherr, M. G., Kodira, C. D., Kohler, A., Kües, U., Lindquist, E. A., Lucas, S. M., Mago, R., Mauceli, E., Morin, E., Murat, C., Pangilinan, J. L., Park, R., Pearson, M., Quesneville, H., Rouhier, N., Sakthikumar, S., Salamov, A. A., Schmutz, J., Selles, B., Shapiro, H., Tanguay, P., Tuskan, G. A., Henrissat, B., Van de Peer, Y., Rouzé, P., Ellis, J. G., Dodds, P. N., Schein, J. E., Zhong, S., Hamelin, R. C., Grigoriev, I. V., Szabo, L. J., and Martin, F. 2011. Obligate biotrophy features unraveled by the genomic analysis of rust fungi. Proc. Natl. Acad. Sci. U.S.A. 108: 9166-9171.

Edgar, R. C. 2004. MUSCLE: A multiple sequence alignment method with reduced time and space complexity. BMC Bioinformatics 5:113.

Haas, B. J., Kamoun, S., Zody, M. C., Jiang, R. H., Handsaker, R. E., Cano, L. M., Grabherr, M., Kodira, C. D., Raffaele, S., Torto-Alalibo, T., Bozkurt, T. O., Ah-Fong, A. M., Alvarado, L., Anderson, V. L., Armstrong, M. R., Avrova, A., Baxter, L., Beynon, J., Boevink, P. C., Bollmann, S. R., Bos, J. I., Bulone, V., Cai, G., Cakir, C., Carrington, J. C., Chawner, M., Conti, L., Costanzo, S., Ewan, R., Fahlgren, N., Fischbach, M. A., Fugelstad, J., Gilroy, E. M., Gnerre, S., Green, P. J., Grenville-Briggs, L. J., Griffith, J., Grünwald, N. J., Horn, K., Horner, N. R., Hu, C. H., Huitema, E., Jeong, D. H., Jones, A. M., Jones, J. D., Jones, R. W., Karlsson, E. K., Kunjeti, S. G., Lamour, K., Liu, Z., Ma, L., Maclean, D., Chibucos, M. C., McDonald, H., McWalters, J., Meijer, H. J., Morgan, W., Morris, P. F., Munro, C. A., O’Neill, K., OspinaGiraldo, M., Pinzón, A., Pritchard, L., Ramsahoye, B., Ren, Q., Restrepo, S., Roy, S., Sadanandom, A., Savidor, A., Schornack, S., Schwartz, D. C., Schumann, U. D., Schwessinger, B., Seyer, L., Sharpe, T., Silvar, C., Song, J., Studholme, D. J., Sykes, S., Thines, M., van de Vondervoort, P. J., Phuntumart, V., Wawra, S., Weide, R., Win, J., Young, C., Zhou, S., Fry, W., Meyers, B. C., van West, P., Ristaino, J., Govers, F., Birch, P. R., Whisson, S. C., Judelson, H. S., and Nusbaum, C. 2009. Genome sequence and analysis of the Irish potato famine pathogen Phytophthora infestans. Nature 461:393-398.

Jacq, C., Alt-Mörbe, J., Andre, B., Arnold, W., Bahr, A., Ballesta, J. P., Bargues, M., Baron, L., Becker, A., Biteau, N., Blöcker, H., Blugeon, C., Boskovic, J., Brandt, P., Brückner, M., Buitrago, M. J., Coster, F., Delaveau, T., del Rey, F., Dujon, B., Eide, L. G., Garcia-Cantalejo, J. M., Goffeau, A., Gomez-Peris, A., Zaccaria, P. et al. 1997. The nucleotide sequence of Saccharomyces cerevisiae chromosome IV. Nature 387: 75-78.

Jiang, R. H., de Bruijn, I., Haas, B. J., Belmonte, R., Löbach, L., Christie, J., van den Ackerveken, G., Bottin, A., Bulone, V., Díaz-Moreno, S. M., Dumas, B., Fan, L., Gaulin, E., Govers, F., Grenville-Briggs, L. J., Horner, N. R., Levin, J. Z., Mammella, M., Meijer, H. J., Morris, P., Nusbaum, C., Oome, S., Phillips, A. J., van Rooyen, D., Rzeszutek, E., Saraiva, M., Secombes, C. J., Seidl, M. F., Snel, B., Stassen, J. H., Sykes, S., Tripathy, S., van den Berg, H., Vega-Arreguin, J. C., Wawra, S., Young, S. K., Zeng, Q., Dieguez-Uribeondo, J., Russ, C., Tyler, B. M., and van West, P. 2013. Distinctive expansion of potential virulence genes in the genome of the oomycete fish pathogen Saprolegnia parasitica. PLoS Genet. 9:e1003272.

Jiang, R. H., Tripathy, S., Govers, F., and Tyler, B. M. 2008. RXLR effector reservoir in two Phytophthora species is dominated by a single rapidly evolving superfamily with more than 700 members. Proc. Natl. Acad. Sci. U.S.A. 105:4874-4879.

Jones, J. D., and Dangl, J. L. 2006. The plant immune system. Nature 444: 323-329.

Kale, S. D., Gu, B., Capelluto, D. G., Dou, D., Feldman, E., Rumore, A., Arredondo, F. D., Hanlon, R., Fudal, I., Rouxel, T., Lawrence, C. B., Shan, W., and Tyler, B. M. 2010. External lipid PI3P mediates entry of eukaryotic pathogen effectors into plant and animal host cells. Cell 142: 284-295. 
Kamoun, S., Furzer, O., Jones, J. D., Judelson, H. S., Ali, G. S., Dalio, R. J., Roy, S. G., Schena, L., Zambounis, A., Panabières, F., Cahill, D., Ruocco, M., Figueiredo, A., Chen, X. R., Hulvey, J., Stam, R., Lamour, K., Gijzen, M., Tyler, B. M., Grünwald, N. J., Mukhtar, M. S., Tomé, D. F., Tör, M., Van Den Ackerveken, G., McDowell, J., Daayf, F., Fry, W. E., Lindqvist-Kreuze, H., Meijer, H. J., Petre, B., Ristaino, J., Yoshida, K., Birch, P. R., and Govers, F. 2015. The top 10 oomycete pathogens in molecular plant pathology. Mol. Plant Pathol. 16: 413-434

Kämper, J., Kahmann, R., Bölker, M., Ma, L. J., Brefort, T., Saville, B. J., Banuett, F., Kronstad, J. W., Gold, S. E., Müller, O., Perlin, M. H., Wösten, H. A., de Vries, R., Ruiz-Herrera, J., Reynaga-Peña, C. G., Snetselaar, K., McCann, M., Pérez-Martín, J., Feldbrügge, M., Basse, C. W., Steinberg, G., Ibeas, J. I., Holloman, W., Guzman, P., Farman, M., Stajich, J. E., Sentandreu, R., González-Prieto, J. M., Kennell, J. C., Molina, L., Schirawski, J., Mendoza-Mendoza, A., Greilinger, D., Münch, K., Rössel, N., Scherer, M., Vranes, M., Ladendorf, O., Vincon, V., Fuchs, U., Sandrock, B., Meng, S., Ho, E. C., Cahill, M. J., Boyce, K. J., Klose, J., Klosterman, S. J., Deelstra, H. J., Ortiz-Castellanos, L., Li, W., Sanchez-Alonso, P., Schreier, P. H., Häuser-Hahn, I., Vaupel, M., Koopmann, E., Friedrich, G., Voss, H., Schlüter, T., Margolis, J., Platt, D., Swimmer, C., Gnirke, A., Chen, F., Vysotskaia, V., Mannhaupt, G., Güldener, U., Münsterkötter, M., Haase, D., Oesterheld, M., Mewes, H. W., Mauceli, E. W., DeCaprio, D., Wade, C. M., Butler, J., Young, S., Jaffe, D. B., Calvo, S., Nusbaum, C., Galagan, J., and Birren, B. W. 2006. Insights from the genome of the biotrophic fungal plant pathogen Ustilago maydis. Nature 444:97-101.

Kanneganti, T. D., Huitema, E., Cakir, C., and Kamoun, S. 2006. Synergistic interactions of the plant cell death pathways induced by Phytophthora infestans Nepl-like protein PiNPP1.1 and INF1 elicitin. Mol. Plant-Microbe Interact. 19:854-863.

Kemen, E., Gardiner, A., Schultz-Larsen, T., Kemen, A. C., Balmuth, A. L., Robert-Seilaniantz, A., Bailey, K., Holub, E., Studholme, D. J., Maclean, D., and Jones, J. D. 2011. Gene gain and loss during evolution of obligate parasitism in the white rust pathogen of Arabidopsis thaliana. PLoS Biol. 9:e1001094.

Krogh, A., Larsson, B., von Heijne, G., and Sonnhammer, E. L. 2001. Predicting transmembrane protein topology with a hidden Markov model: Application to complete genomes. J. Mol. Biol. 305:567-580.

Kushwaha, S. K., Vetukuri, R. R., and Grenville-Briggs, L. J. 2017. Draft genome sequence of the mycoparasitic oomycete Pythium oligandrum strain CBS 530.74. Genome Announc. 5:e00346-17.

Latijnhouwers, M., de Wit, P. J., and Govers, F. 2003. Oomycetes and fungi: Similar weaponry to attack plants. Trends Microbiol. 11:462-469.

Lévesque, C. A., Brouwer, H., Cano, L., Hamilton, J. P., Holt, C., Huitema, E., Raffaele, S., Robideau, G. P., Thines, M., Win, J., Zerillo, M. M., Beakes, G. W., Boore, J. L., Busam, D., Dumas, B., Ferriera, S., Fuerstenberg, S. I., Gachon, C. M., Gaulin, E., Govers, F., GrenvilleBriggs, L., Horner, N., Hostetler, J., Jiang, R. H., Johnson, J., Krajaejun, T., Lin, H., Meijer, H. J., Moore, B., Morris, P., Phuntmart, V., Puiu, D., Shetty, J., Stajich, J. E., Tripathy, S., Wawra, S., van West, P., Whitty, B. R., Coutinho, P. M., Henrissat, B., Martin, F., Thomas, P. D., Tyler, B. M., De Vries, R. P., Kamoun, S., Yandell, M., Tisserat, N., and Buell, C. R. 2010. Genome sequence of the necrotrophic plant pathogen Pythium ultimum reveals original pathogenicity mechanisms and effector repertoire. Genome Biol. 11:R73.

Li, H., Handsaker, B., Wysoker, A., Fennell, T., Ruan, J., Homer, N., Marth, G., Abecasis, G., Durbin, R., and 1000 Genome Project Data Processing Subgroup. 2009. The Sequence Alignment/Map format and SAMtools. Bioinformatics 25:2078-2079.

Li, Q., Ai, G., Shen, D., Zou, F., Wang, J., Bai, T., Chen, Y., Li, S., Zhang, M., Jing, M., and Dou, D. 2019. A Phytophthora capsici effector targets ACD11 binding partners that regulate ROS-mediated defense response in Arabidopsis. Mol. Plant 12:565-581.

Links, M. G., Holub, E., Jiang, R. H., Sharpe, A. G., Hegedus, D., Beynon, E., Sillito, D., Clarke, W. E., Uzuhashi, S., and Borhan, M. H. 2011. De novo sequence assembly of Albugo candida reveals a small genome relative to other biotrophic oomycetes. BMC Genomics 12:503.

McCarthy, C. G. P., and Fitzpatrick, D. A. 2017. Phylogenomic reconstruction of the oomycete phylogeny derived from 37 genomes. MSphere 2:e00095-17.

Monaghan, J., and Zipfel, C. 2012. Plant pattern recognition receptor complexes at the plasma membrane. Curr. Opin. Plant Biol. 15:349-357.

Nguyen, L. T., Schmidt, H. A., von Haeseler, A., and Minh, B. Q. 2015. IQTREE: A fast and effective stochastic algorithm for estimating maximum-likelihood phylogenies. Mol. Biol. Evol. 32:268-274.

Opperman, C. H., Bird, D. M., Williamson, V. M., Rokhsar, D. S., Burke, M., Cohn, J., Cromer, J., Diener, S., Gajan, J., Graham, S., Houfek, T. D.,
Liu, Q., Mitros, T., Schaff, J., Schaffer, R., Scholl, E., Sosinski, B. R., Thomas, V. P., and Windham, E. 2008. Sequence and genetic map of Meloidogyne hapla: A compact nematode genome for plant parasitism. Proc. Natl. Acad. Sci. U.S.A. 105:14802-14807.

Paul, B. 1999. Pythium periplocum, an aggressive mycoparasite of Botrytis cinerea causing the gray mould disease of grape-vine. FEMS Microbiol. Lett. 181:277-280.

Pertea, M., Kim, D., Pertea, G. M., Leek, J. T., and Salzberg, S. L. 2016. Transcript-level expression analysis of RNA-seq experiments with HISAT, StringTie and Ballgown. Nat. Protoc. 11:1650-1667.

Qi, J., Wang, J., Gong, Z., and Zhou, J. M. 2017. Apoplastic ROS signaling in plant immunity. Curr. Opin. Plant Biol. 38:92-100.

Raffaele, S., Farrer, R. A., Cano, L. M., Studholme, D. J., MacLean, D. Thines, M., Jiang, R. H., Zody, M. C., Kunjeti, S. G., Donofrio, N. M., Meyers, B. C., Nusbaum, C., and Kamoun, S. 2010. Genome evolution following host jumps in the Irish potato famine pathogen lineage. Science 330:1540-1543.

Raffaele, S., and Kamoun, S. 2012. Genome evolution in filamentous plant pathogens: Why bigger can be better. Nat. Rev. Microbiol. 10: 417-430.

Rujirawat, T., Patumcharoenpol, P., Lohnoo, T., Yingyong, W., Kumsang, Y., Payattikul, P., Tangphatsornruang, S., Suriyaphol, P., Reamtong, O., Garg, G., Kittichotirat, W., and Krajaejun, T. 2018. Probing the phylogenomics and putative pathogenicity genes of Pythium insidiosum by oomycete genome analyses. Sci. Rep. 8:4135.

Saeed, A. I., Sharov, V., White, J., Li, J., Liang, W., Bhagabati, N., Braisted, J., Klapa, M., Currier, T., Thiagarajan, M., Sturn, A., Snuffin, M., Rezantsev, A., Popov, D., Ryltsov, A., Kostukovich, E., Borisovsky, I., Liu, Z., Vinsavich, A., Trush, V., and Quackenbush, J. 2003. TM4: A free, open-source system for microarray data management and analysis. Biotechniques 34:374-378.

Shen, D., Li, Q., Sun, P., Zhang, M., and Dou, D. 2017. Intrinsic disorder is a common structural characteristic of RxLR effectors in oomycete pathogens. Fungal Biol. 121:911-919.

Shen, D., Tang, Z., Wang, C., Wang, J., Dong, Y., Chen, Y., Wei, Y., Cheng, B., Zhang, M., Grenville-Briggs, L. J., Tyler, B. M., Dou, D., and Xia, A. 2019. Infection mechanisms and putative effector repertoire of the mosquito pathogenic oomycete Pythium guiyangense uncovered by genomic analysis. PLoS Genet. 15:e1008116.

Smits, T. H., Rezzonico, F., Kamber, T., Blom, J., Goesmann, A., Frey, J. E., and Duffy, B. 2010. Complete genome sequence of the fire blight pathogen Erwinia amylovora CFBP 1430 and comparison to other Erwinia spp. Mol. Plant-Microbe Interact. 23:384-393.

Song, T., Ma, Z., Shen, D., Li, Q., Li, W., Su, L., Ye, T., Zhang, M., Wang, Y., and Dou, D. 2015. An oomycete CRN effector reprograms expression of plant HSP genes by targeting their promoters. PLoS Pathog. 11:e1005348.

Subramanian, B., Gao, S., Lercher, M. J., Hu, S., and Chen, W. H. 2019. Evolview v3: A webserver for visualization, annotation, and management of phylogenetic trees. Nucleic Acids Res. 47 (W1):W270-W275.

Takenaka, S., Nishio, Z., and Nakamura, Y. 2003. Induction of defense reactions in sugar beet and wheat by treatment with cell wall protein fractions from the mycoparasite Pythium oligandrum. Phytopathology 93:1228-1232.

Tyler, B. M., Tripathy, S., Zhang, X., Dehal, P., Jiang, R. H., Aerts, A., Arredondo, F. D., Baxter, L., Bensasson, D., Beynon, J. L., Chapman, J., Damasceno, C. M., Dorrance, A. E., Dou, D., Dickerman, A. W., Dubchak, I. L., Garbelotto, M., Gijzen, M., Gordon, S. G., Govers, F., Grunwald, N. J., Huang, W., Ivors, K. L., Jones, R. W., Kamoun, S., Krampis, K., Lamour, K. H., Lee, M. K., McDonald, W. H., Medina, M., Meijer, H. J., Nordberg, E. K., Maclean, D. J., Ospina-Giraldo, M. D., Morris, P. F., Phuntumart, V., Putnam, N. H., Rash, S., Rose, J. K., Sakihama, Y., Salamov, A. A., Savidor, A., Scheuring, C. F., Smith, B. M., Sobral, B. W., Terry, A., Torto-Alalibo, T. A., Win, J., Xu, Z., Zhang, H., Grigoriev, I. V., Rokhsar, D. S., and Boore, J. L. 2006. Phytophthora genome sequences uncover evolutionary origins and mechanisms of pathogenesis. Science 313:1261-1266.

Van Kan, J. A., Stassen, J. H., Mosbach, A., Van Der Lee, T. A., Faino, L., Farmer, A. D., Papasotiriou, D. G., Zhou, S., Seidl, M. F., Cottam, E., Edel, D., Hahn, M., Schwartz, D. C., Dietrich, R. A., Widdison, S., and Scalliet, G. 2017. A gapless genome sequence of the fungus Botrytis cinerea. Mol. Plant Pathol. 18:75-89.

Walsh, I., Martin, A. J., Di Domenico, T., and Tosatto, S. C. 2012. ESpritz: Accurate and fast prediction of protein disorder. Bioinformatics 28: 503-509.

Wang, Q., Han, C., Ferreira, A. O., Yu, X., Ye, W., Tripathy, S., Kale, S. D., Gu, B., Sheng, Y., Sui, Y., Wang, X., Zhang, Z., Cheng, B., Dong, S., Shan, W., Zheng, X., Dou, D., Tyler, B. M., and Wang, Y. 2011. 
Transcriptional programming and functional interactions within the Phytophthora sojae RXLR effector repertoire. Plant Cell 23:2064-2086.

Wang, Y., Tang, H., Debarry, J. D., Tan, X., Li, J., Wang, X., Lee, T. H., Jin, H., Marler, B., Guo, H., Kissinger, J. C., and Paterson, A. H. 2012. MCScanX: A toolkit for detection and evolutionary analysis of gene synteny and collinearity. Nucleic Acids Res. 40:e49.

Wawra, S., Bain, J., Durward, E., de Bruijn, I., Minor, K. L., Matena, A., Löbach, L., Whisson, S. C., Bayer, P., Porter, A. J., Birch, P. R. Secombes, C. J., and van West, P. 2012. Host-targeting protein 1 (SpHtp1) from the oomycete Saprolegnia parasitica translocates specifically into fish cells in a tyrosine-O-sulphate-dependent manner. Proc. Natl. Acad. Sci. U.S.A. 109:2096-2101.

Whisson, S. C., Boevink, P. C., Moleleki, L., Avrova, A. O., Morales, J. G., Gilroy, E. M., Armstrong, M. R., Grouffaud, S., van West, P., Chapman, S., Hein, I., Toth, I. K., Pritchard, L., and Birch, P. R. 2007. A translocation signal for delivery of oomycete effector proteins into host plant cells. Nature 450:115-118.

Win, J., Morgan, W., Bos, J., Krasileva, K. V., Cano, L. M., ChaparroGarcia, A., Ammar, R., Staskawicz, B. J., and Kamoun, S. 2007. Adaptive evolution has targeted the C-terminal domain of the RXLR effectors of plant pathogenic oomycetes. Plant Cell 19: 2349-2369.

Yin, L., An, Y., Qu, J., Li, X., Zhang, Y., Dry, I., Wu, H., and Lu, J. 2017. Genome sequence of Plasmopara viticola and insight into the pathogenic mechanism. Sci. Rep. 7:46553.

Zheng, X., McLellan, H., Fraiture, M., Liu, X., Boevink, P. C., Gilroy, E. M., Chen, Y., Kandel, K., Sessa, G., Birch, P. R., and Brunner, F. 2014 Functionally redundant RXLR effectors from Phytophthora infestans act at different steps to suppress early flg22-triggered immunity. PLoS Pathog. 10:e1004057. 